\title{
Identification of miRNAs involved in pear fruit development and quality
}

\author{
Jun $\mathrm{Wu}^{1 *+}$, Defu Wang ${ }^{1 \dagger}$, Yufeng Liu², Long Wang ${ }^{1}$, Xin Qiao ${ }^{1}$ and Shaoling Zhang ${ }^{1 *}$
}

\begin{abstract}
Background: MicroRNAs (miRNAs) are a class of small, endogenous RNAs that take part in regulating genes through mediating gene expressions at the post-transcriptional level in plants. Previous studies have reported miRNA identification in various plants ranging from model plants to perennial fruit trees. However, the role of miRNAs in pear (Pyrus bretschneideri) fruit development is not clear. Here, we investigated the miRNA profiles of pear fruits from different time stages during development with Illumina HiSeq 2000 platform and bioinformatics analysis. Quantitative real-time PCR was used to validate the expression levels of miRNAs.

Results: Both conserved and species-specific miRNAs in pear have been identified in this study. Total reads, ranging from 19,030,925 to 25,576,773, were obtained from six small RNA libraries constructed for different stages of fruit development after flowering. Comparative profiling showed that an average of 90 miRNAs was expressed with significant differences between various developmental stages. KEGG pathway analysis on 2,216 target genes of 188 known miRNAs and 1,127 target genes of 184 novel miRNAs showed that miRNAs are widely involved in the regulation of fruit development. Among these, a total of eleven miRNAs putatively participate in the pathway of lignin biosynthesis, nine miRNAs were identified to take part in sugar and acid metabolism, and MiR160 was identified to regulate auxin response factor.

Conclusion: Comparative analysis of miRNAomes during pear fruit development is presented, and miRNAs were proved to be widely involved in the regulation of fruit development and formation of fruit quality, for example through lignin synthesis, sugar and acid metabolism, and hormone signaling. Combined with computational analysis and experimental confirmation, the research contributes valuable information for further functional research of microRNA in fruit development for pear and other species.
\end{abstract}

Keywords: Pear, Fruit development, High-throughput sequencing, miRNA, Lignin synthesis, Sugar and acid

\section{Background}

Since the identification of the first microRNAs (miRNAs) as key regulatory molecules in the pathway controlling the timing of larval development in Caenorhabditis elegans [1], great progress has been made in the understanding of miRNA function in various species. Ha and Kim reported the biogenesis of miRNA in animals and pointed out that dis-regulation of miRNAs is associated with many human diseases [2]. In plants, the molecular events underlying miRNA biogenesis and degradation, and miRNA-mediated

\footnotetext{
*Correspondence: wujun@njau.edu.cn; slzhang@njau.edu.cn

${ }^{\dagger}$ Equal contributors

'College of Horticulture, State Key Laboratory of Crop Genetics and Germplasm Enhancement, Nanjing Agricultural University, Nanjing 210095, China

Full list of author information is available at the end of the article
}

gene silencing were also reported [3], such as, MiRNAs are involved in plant development, signaling, abiotic stresses and symbiotic relationship regulation [4]. Intensive studies indicate that miRNAs are involved in post-transcriptional regulation and appear to be one of the most significant regulatory mechanisms [1,5]. Currently, more than 30,424 mature miRNAs have been identified from 206 species including vertebrates, flies, worms, plants and viruses (miRBase release 20, June 2013, http://www.mirbase. org/). High evolutionary conservation among different plant species provides the premise for miRNA identification. In plants, miRNAs are single strand, usually 21-22 nt long small RNA molecules that are processed by Dicer-like 1(DCL1). MiRNA/miRNA* duplexes, which contain the mature miRNA, are processed from premiRNA which is produced from primary miRNA [6]. One 
of the strands of the generated miRNA/miRNA* duplex is incorporated into the RNA-induced silencing complex (RISC). This strand is usually the mature miRNA strand and the miRNA* strand gets degraded [7]. By cleavage of target mRNAs [8], translational repression [9] or transcriptional inhibition [10], mature miRNAs suppress the expression of their target genes. Some plant miRNAs physically clustered together as a polycistron, suggesting that these miRNAs potentially regulate gene expression coordinately [7].

A number of studies have suggested that miRNAs play an important role in regulating development of plants, the response to environment and many other biochemical reactions [11-15]. For example, Gao et al. [16] reported that miR319/miR319a/miR319e may contribute to an increase in imperfect flower ratios in the pistil of Japanese apricot development. MiR172 functions in regulating the transition between developmental stages and in specifying floral organ identity by regulating expression of AP2-domaincontaining transcription factors in monocots and dicots [17]. Karlova et al. [18] reported that CNR and SIAP2a, known as the auxin response factor (ARF) and ripening regulators, were actively modulated by miR156/157 and miR172 during tomato ripening. Moxon et al. [19] validated that a member of the constitutive triple response (CTR) family is involved in tomato fruit ripening, which is the target of the novel miRNA, and a higher expression pattern of miR390 was found in small fruit than in leaves and flowers. Over expressing an AtMIR156b precursor generated abnormal flower and fruit morphology in tomato by targeting S.lycopersicum SBP genes [20]. Itaya et al. [21] reported that miR167 is involved in auxin response and APETALA2 (AP2) was the target gene of miR172. In strawberry [8], two members of miR159 (Fa-miR159a and Fa-miR159b) were identified interacting with $F a-G A M Y B$ during the course of berry receptacle development and cooperatively changed GA endogenous levels. In sweet orange, Csi-miR164 showed a high expression level in fruit ripening and targeted the NAC transcription factor [22].

Pear (Pyrus spp) with more than 3,000 years of cultivation history is regarded as one of the most important fruit crops and cultivated worldwide in 76 countries. Rich in vitamin $C$, dietary fiber, sugar, protein, and many other nutrients, pear fruit has consistently been consumed fresh, canned, and dried and is believed to benefit human health. Small RNAs have been annotated for pear genome in our previous research study [23], and the genome wide identification of pear miRNAs was recently reported recently [24]. However, the function of miRNAs in pear fruit development remains unknown and specific miRNAs for fruit are expected to be identified. In this study, we investigated the miRNA profiles of pear fruits from different developmental stages with Illumina HiSeq 2000 platform, combined with bioinformatics analysis and experimental verification, and it is the first to prove that miRNAs are widely involved in the regulation of pear fruit development and quality.

\section{Results and discussion}

\section{Small RNA library preparation and sequencing}

Total RNA extracted from pear fruit samples, which were collected at different developmental stages from 15 days after flowering (DAF) to 167 DAF, was employed to build small RNA libraries for sequencing. Total reads, ranging from 19 million to 25 million of the six libraries, were generated from Illumina HiSeq 2000 (Table 1). After removing adaptors, poly $\mathrm{A}$ reads and reads of less than $18 \mathrm{nt}$, clean reads varied from 18 million to 25 million, which occupied on average $97.81 \%$ in total reads of the six libraries, were collected. Approximately $3.29 \%(747,350)$ of the clean reads could be mapped to known noncoding RNAs (rRNA, snRNA, snoRNA, tRNA) deposited in the NCBI. There were $1,217,957$ reads on

Table 1 Categorization of reads of small RNAs in pear fruit at various developmental stages DAF: days after flowering

\begin{tabular}{|c|c|c|c|c|c|c|c|}
\hline \multirow{2}{*}{ Category } & \multicolumn{6}{|c|}{ Development stages } & \multirow{2}{*}{ Average } \\
\hline & 15DAF & $36 \mathrm{DAF}$ & $81 \mathrm{DAF}$ & $110 \mathrm{DAF}$ & $145 \mathrm{DAF}$ & 167 DAF & \\
\hline Total reads & $22,354,861$ & $23,934,357$ & $19,030,925$ & $25,576,773$ & $23,934,213$ & $24,527,030$ & $23,226,360$ \\
\hline Clean reads & $21,612,084$ & $23,153,525$ & $18,618,514$ & $25,086,346$ & $23,575,395$ & $24,263,969$ & $22,718,306$ \\
\hline Exon_antisense & 319,460 & 308,465 & 218,280 & 257,309 & 215,078 & 220,482 & 256,512 \\
\hline Exon_sense & 509,150 & 453,742 & 341,272 & 398,473 & 365,311 & 350,102 & 403,008 \\
\hline Intron_antisense & 377,104 & 395,221 & 298,440 & 378,094 & 331,083 & 360,635 & 356,763 \\
\hline Intron_sense & 797,178 & 619,168 & 528,500 & 614,109 & 662,064 & 599,612 & 636,772 \\
\hline Known miRNAs & $1,147,166$ & $1,014,459$ & $1,271,600$ & $1,590,575$ & $1,170,540$ & $1,113,401$ & $1,217,957$ \\
\hline rRNA etc.* & $1,158,744$ & 756,242 & 617,356 & 708,315 & 607,519 & 635,925 & 747,350 \\
\hline Repeat & $9,514,359$ & $10,881,244$ & $8,544,263$ & $11,564,973$ & $11,161,868$ & $11,351,321$ & $10,503,005$ \\
\hline Un-annotated & $7,788,923$ & $8,724,984$ & $6,798,803$ & $9,574,498$ & $9,061,932$ & $9,632,491$ & $8,596,939$ \\
\hline
\end{tabular}


average identified to be putative known miRNAs, and an average of 8,596,939 identified to be un-annotated miRNAs (Table 1). Using SOAP2 software, more than 15 million clean reads $(69.335 \%)$ were perfectly mapped to the pear genome [23].

The number of reads with different lengths of the six small RNA libraries was counted (Figure 1). It was observed that small RNAs with length ranging from $21 \mathrm{nt}$ to 24 nt were most frequent (nearly $90 \%$ ) of all the clean reads of each library, with 24 nt the most abundant (close to 50\%) small RNA length, followed by $23 \mathrm{nt}$, $21 \mathrm{nt}$, and $20 \mathrm{nt}$, in that order. The result was consistent with previous reports in various species, including tomato [19], Arabidopsis thaliana [25,26], Citrus trifoliate [27], Medicago truncatula [28,29], Citrus sativus [30], and maize [10] which all suggest the most abundant small RNA length is $24 \mathrm{nt}$.

\section{Identification of conserved miRNAs in pear fruit}

In order to identify the known miRNAs in pear fruit, the clean reads of each library were compared to other plant miRNAs deposited in miRBase 20.0. Following the BLASTn searches and further sequence analysis, on average more than 1 million total reads for six libraries were perfectly matched to 362 known miRNAs (Additional file 1). Among these, 60 miRNAs were identified as 55 known miRNA families deposited in miRBase. The numbers of miRNA in one miRNA family were various. As listed in Additional file 1, five families, including miR156, miR164, miR167, miR2111 and miR4414, have two miRNAs each. The rest of the 50 families have one miRNA each, and there were 302 conserved miRNAs with no match to any family, possibly due to the variation between different species.

The location of 362 conserved miRNA was shown according to the pear genome data (Additional file 1).
From these, 266 miRNAs were located on chromosomes or scaffolds, and multiple transcript sites for all 266 miRNAs ensured the miRNA gene expression and important regulation function. However, this result showed great difference with rice, in which $69 \%$ of mapped small RNAs have a unique genome location [9]. Whether the multiple or unique transcripts of miRNA have a special function is still unknown. The remaining 96 pear fruit miRNAs did not map to chromosome sites due to incomplete genome annotation. Except for the 96 miRNAs with unknown transcript sites, miR4250 had the most transcript sites with 2,352 .

In previous studies of pear [24], 186 conserved pear miRNAs and 37 miRNA families were identified. Comparatively, there were 21 of the same miRNA families (miR156, miR157, miR164, miR166, miR167, miR168, miR172, miR2111, miR319, miR390, miR394, miR395, miR396, miR397, miR398, miR399, miR408, miR4414, miR477, miR535, miR827) found in our research. Additionally, miR156 was shown to be the largest miRNA family in pear. In Japanese apricot [15] and peanut [31], miR156 was also found to be the largest miRNA family of all the identified miRNA families. The result may suggest the fundamental function played by miR156 across various species.

The analysis of read counts for known miRNA families suggested the great expression frequency divergences among these miRNAs. With respect to the abundance of each miRNA family, the frequencies varied from 2 to 368,116 reads, indicating that expression varies significantly among different miRNA families. In the six libraries, miR165a showed the highest sequencing reads, which may suggest the largest expression in pear fruit among miRNA families. The varied abundance is also identified in certain members from the same family. For example, the abundance of miR167 varied from 8 to

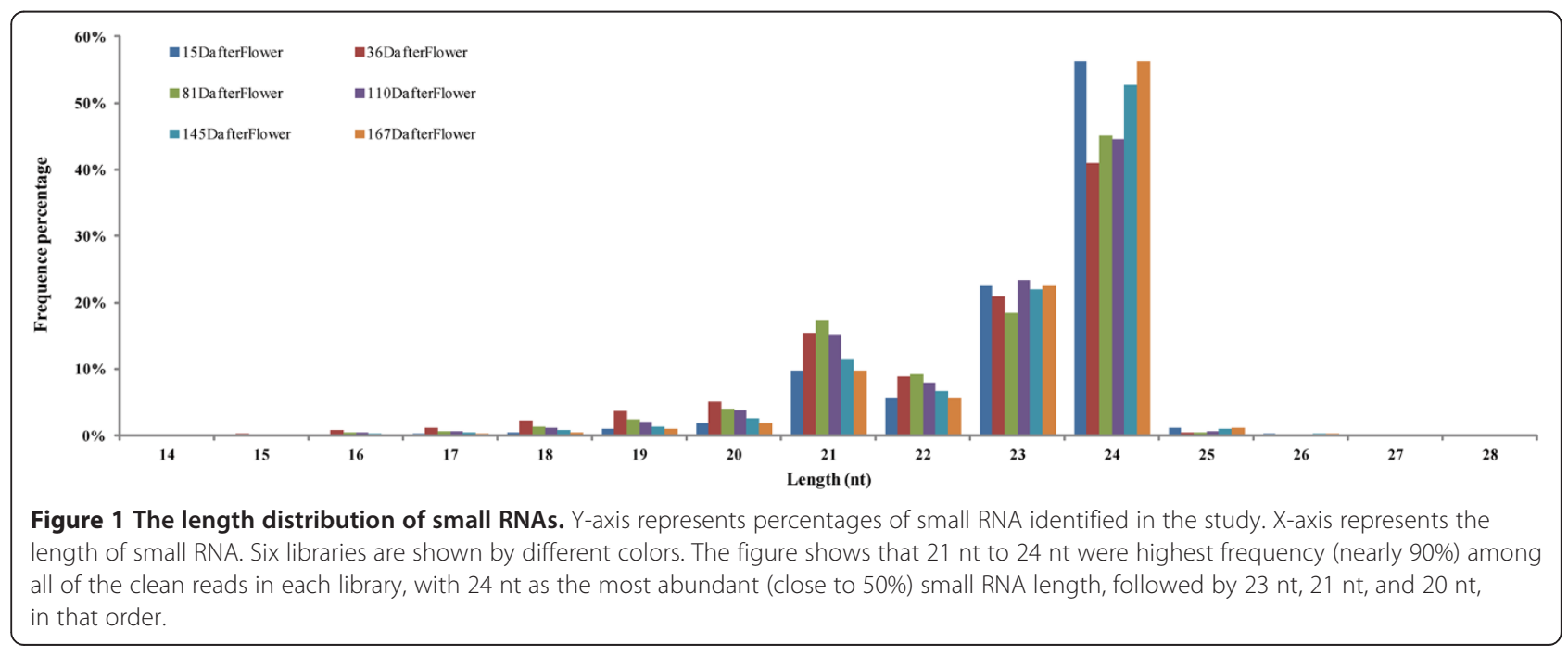


4,598 reads in 110 DAF library, as was the case for some other families, including miR156 (6 to 70,015 reads) and miR164 (45 to 28,900 reads). The two members of the miR4414 family showed distinct sequencing reads, miR4414a with 33,340 and miR4414a* with 2 in 15 DAF library. The two members of the miR164 family also observed the similar phenomenon at the 15 DAF library, miR164a showed abundance with 46,332 and miR164c* with 33. The results indicate that expression levels of different members within one miRNA family varied greatly during fruit development. In addition, the multiple locations for the same miRNA varieties also suggests there were many transcript sites for each miRNA in the genome, so there was a choice of member to transcribe in the same miRNA family, which may explain the expression variation.

\section{Identification of novel miRNAs in pear fruit}

MIREAP software was used to predict novel miRNAs in fruit by exploring the secondary structure compared with whole genome data [23]. 178,944 total reads and 654 unique reads were identified as novel miRNAs. There were 297 novel miRNAs in total and 41 of them classified into 16 different known miRNA families. Precursors forming hairpin structures were obtained. The average negative minimal folding free energy (MFE) was $-51.48 \mathrm{kcal} / \mathrm{mol}$ (Additional file 2), which was similar to the sequencing data for maize miRNA precursors (-61.15 kcal/mol) [10] and Arabidopsis thaliana miRNA precursors $(-57 \mathrm{kcal} / \mathrm{mol})$ [4]. The length of the novel miRNA precursors was identified to range from 64 to $374 \mathrm{nt}$, which was quite close to Japanese apricot [15]. As previous reported plant miRNA prefers the length 21 nt with the $5^{\prime}$ end base bias to uracil (U) [32]. In our research, we also found base biases of 21 nt of novel miRNA showing the similar pattern, the $U$ nucleotide took the leading percentage (37.05\%), followed by $\mathrm{A}$ (31\%), G (17.6\%) and $C(14.35 \%)$ in the six libraries (Figure 2).

\section{Validation of microRNA expression by qRT-PCR}

In our research, $\mathrm{qPCR}$ was adopted to validate the sequencing results of six miRNAs (miR166a, miR4376-5p, miR156k, miR396b-3p, miR164c*, miR159b-3p), and was able to show that these miRNA are really expressed, and the changes during the fruit development are real. The line charts indicate similar expression patterns as shown in Figure 3, although the values of miRNA expression detected by two methods varied to some extent. So, the qPCR results confirmed the reliability and expression patterns of microRNA involved in pear fruit development through high throughput sequencing.

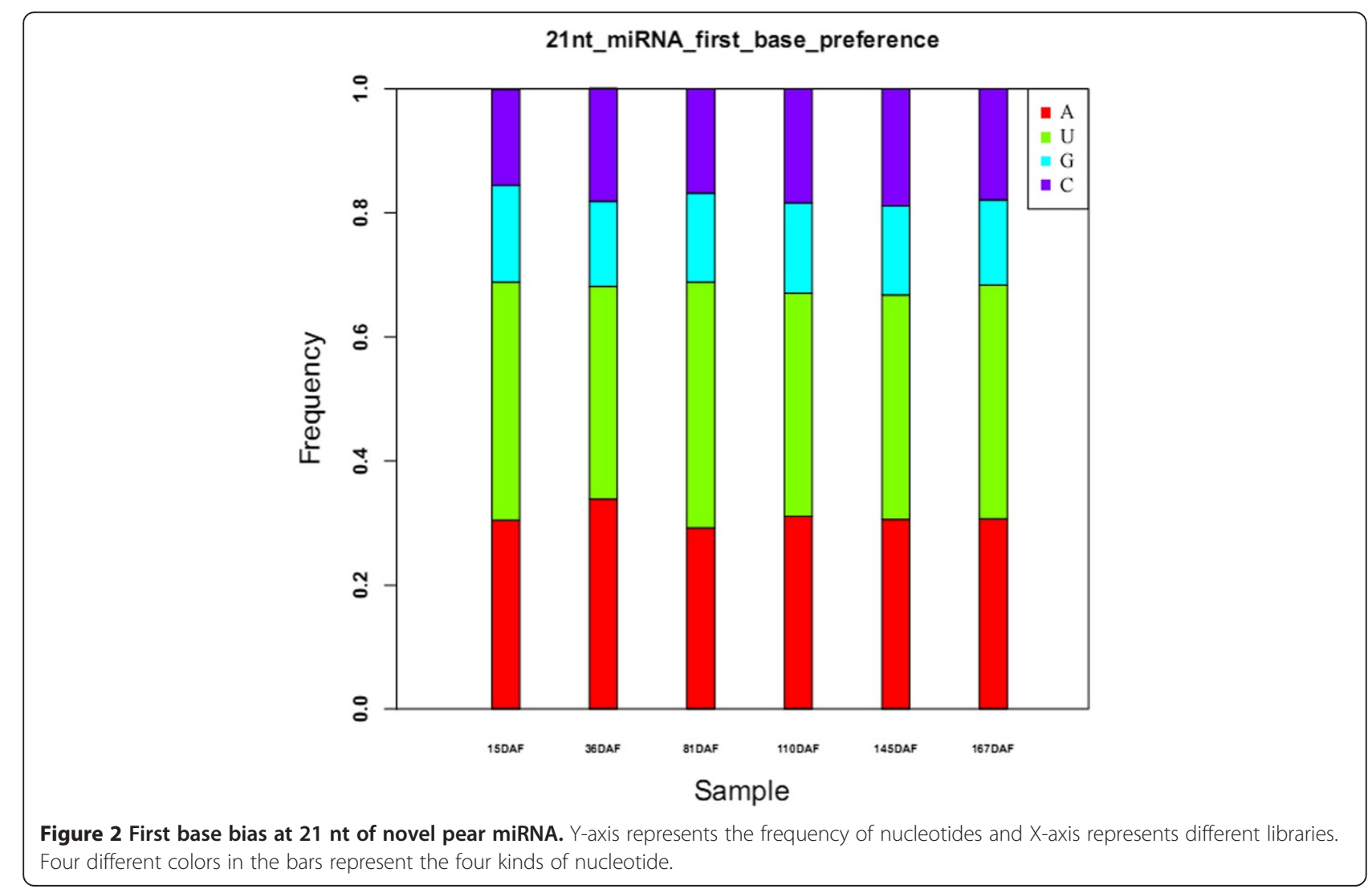



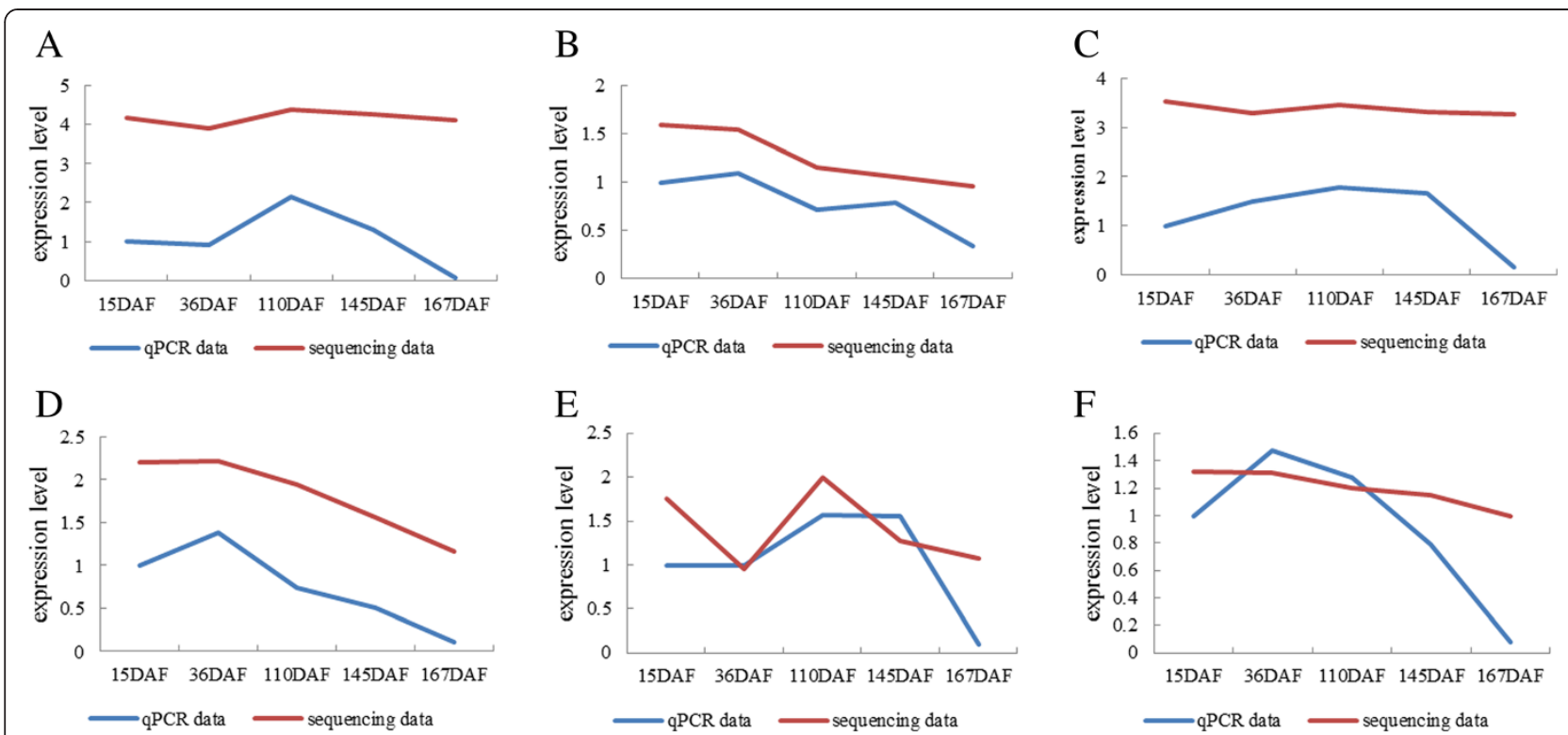

Figure 3 Expression pattern confirmed by qRT-PCR and comparison with sequencing data. Relative expression pattern of six different conserved miRNAs among various libraries are confirmed by qRT-PCR results by $2^{-\Delta \Delta C t}$ method. For visualization, log 10 method is applied to compute the TPM data of sequencing results. The paragraph $\mathbf{A}$ to $\mathbf{F}$ represent the expression profiles of miR166a, miR4376-5p, miR156k, miR396b-3p, miR164c* and miR159b-3p in sequence. Y-axis represents the expression level and X-axis represents different libraries. Blue lines represent the q-PCR data and red lines represent the sequencing data. The line charts indicate the similar expression patterns with miRNA sequencing.

\section{MiRNAs mapped on pear genome reference}

Using SOAP2 software, more than 15 million clean reads (69.335\%) were perfectly mapped to the pear genome [23]. Compared with 297 miRNAs identified in pear genome [18], there were 15 newly discovered conserved miRNA families which may suggest expression specifically in pear fruit, including miR156, miR157, miR160, miR166, miR172, miR2118, miR2590, miR319, miR395, miR399, miR4376, miR4414, miR447, miR479, and miR827. Among them, miR4376 has been suggested to regulate transgenic tomato flower morphology and fruit yield by targeting $\mathrm{Ca}^{2+}$-ATPase, SI ACA10 [33]. MiR2118 was not detected in the libraries derived from seedlings, root apices and leaves, but could be detected in libraries derived from early development stages of maize anthers [34,35]. Johnson et al. [9] proposed that miR2118 regulated the development of reproductive structures in cereals. Previous research indicated that these miRNAs showed tissue-specific expression pattern and may play significant roles in plant specific tissue development. However, accurate roles for these miRNAs in pear fruit still need further experimental verification.

When mapping the miRNAs against pear genome reference sequences [23], 266 out of the 362 pear miRNAs could be identified on $\sim 512 \mathrm{Mbp}$ pear genome. The mapping result showed that a single miRNA might have more than one homolog. In the Additional file 3, data showed that all 17 chromosomes had miRNAs distribution on both sense and anti-sense strands, but with uneven distribution of miRNAs. The sense and anti-sense strands of Chr15 had the greatest number of reads, while Chr1 had the least number of reads. The results indicated that miRNAs have uneven distribution on different chromosomes of pear.

MiRNAs were proven to present in clusters. In human, the mir17 cluster contains six precursor miRNAs within about $1 \mathrm{~kb}$ on chromosome 13 [36]. Meanwhile, 25.35\% in Arabidopsis thaliana, 17.09\% in Populus trichocarpa, $22.29 \%$ in Oryza sativa and $21.62 \%$ in Sorghum bicolor of miRNAs have been found to cluster within a 10-kb region in previous studies [37]. In this study, we found 14 miRNA clusters at distances of $10 \mathrm{~kb}$ and 66 clusters at $100 \mathrm{~kb}$ (Additional file 4). The clustering phenomenon is distributed on different regions of the genome. Furthermore, different miRNAs in the same cluster were shown to keep similar expression patterns, as previously reported [38]. Thus the targets of miRNAs in the cluster were shown to have the same function. MiRNA genes are clustered in the genome with an arrangement and expression pattern implying transcription as a multi-cistronic primary transcript. Li et al. suggested that the co-transcription of similar or identical miRNAs in clusters for plants may be involved in gene dosage effect [39]. When compared with previous studies in microRNA identification of pear by Niu et al. [24], no similar clusters were found.

MiRNAs comparison across pear and other plant species MiRNAs in various plants, including several important fruit crops have been identified with next-generation 
sequencing technology. For instance, in apple, a total of 165 miRNAs were identified according to The Apple Gene Function \& Gene Family DataBase v1.0 http://www. applegene.org/mirna.asp. In another Rosaceae plant, peach, 117 conserved miRNAs and 186 novel miRNA candidates have been identified [40]. In our analysis, 362 conserved miRNAs and 297 novel miRNAs were identified in pear, respectively. The variation of miRNAs in our research can give insight to widely existing highly-conserved miRNAs and can give a basis to further deep bioinformatics studies for miRNAs in pear, for instance the SNP identification of miRNAs.

The conservation and divergence of miRNAs among various plant species has been widely reported $[41,42]$. In Jones-Rhoades' study, miR156/157, miR172 and miR170/
171 were regarded as highly conserved miRNAs, with orthologs in more than ten different plant families, while miR163 and miR158 were identified as non-conserved miRNAs [41]. In the perspective of Zhang et al. [7], the varied conservation of miRNAs suggests the multiple functions of miRNAs in plant development, and the miRNAs with low conservation may have species-specific characteristics in plant development.

To study the conservation and evolution of the known miRNAs in pear fruit, comparisons were conducted among eleven other species including Physcomitrella patens, Triticum aestivum, Arabidopsis lyrata, Oryza sativa, Sorghum bicolor, Zea mays, Brassica napus, Prunus persica, Citrus sinensis, Malue domestica, and Vitis vinifera (Figure 4). Based on the analysis, several miRNAs showed a high level

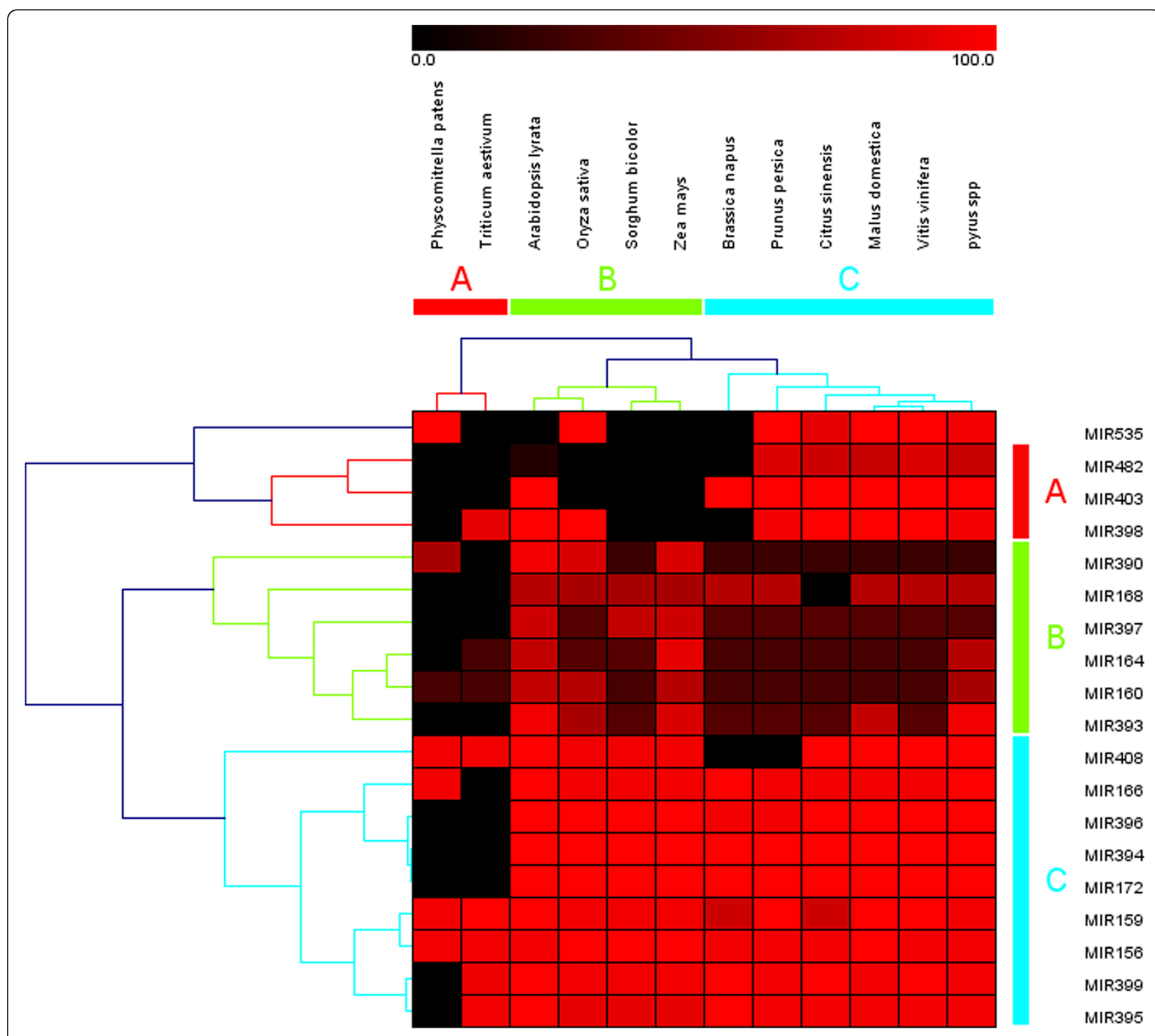

Figure 4 Nineteen conserved miRNAs from pear fruit and their homologs in 11 other plant species. The color shows the homology of miRNAs among the twelve plants. As the color gets closer to bright red, the relationship of the species gets closer to each other. 
of conservation among various plant species, including miR395, miR399, miR156, miR159, miR172, miR394, miR396 and miR166, as more than ten plant species showed high sequence homology for these miRNAs. As expected, Pyrus and Malus domestica shared more than thirteen common conserved miRNA families, exhibiting higher conservation of miRNA families and high homology between the two species. On the converse, with less than five homologous miRNAs, Physcomitrella patens showed narrow homology relationship with Pyrus. The phenomenon can be explained by speciation of plants which was accompanied with the specialization of miRNAs playing species-specific roles [35,42].

\section{Analysis of differentially expressed miRNAs}

Differentially expressed miRNAs were identified by comparing the sequencing reads with significant correlations $(P<0.05$ and $P<0.01)$ between the six libraries. Taking 15 DAF as control, 42 to 149 miRNAs had significant changes among different libraries. Among those miRNAs, there were two (miR839*, miR1871) and twelve miRNAs (miR1087, miR1310, miR169j*, miR2916, miR2936, miR319e, miR3627, miR395a, miR397a, miR398b, miR408, miR408b*) showing an increased or decreased abundance, respectively, from 15DAF to 167DAF. Additionally, the fluctuation patterns of mature miRNAs during the developmental stages were observed, all 362 conserved miRNAs were clustered by their expression patterns (Additional file 5). Taking the early stage (15DAF) as control, there were groups of miRNAs showing higher expression levels at later stages (36DAF to 167DAF), such as miR808, miR1028a-5p, miR1870-3p, miR5255, and miR5253. On the contrary, several miRNAs showed a gradually decreasing expression accompanying fruit development, including miR398a*, miR5245, miR5065, miR413, miR390a, miR167, miR393, miR164, and miR160. Thus, the differential expression patterns of miRNA for different fruit developmental stages in pear were confirmed in this study. The difference in expression profiles may suggest the relationship between miRNAs and pear fruit development. At specific developmental stages, different miRNAs may have the same expression pattern, which may lead to their co-regulatory role in fruit development. As for apple [43], compared with conserved miRNAs, novel miRNAs exhibited lower expression levels in pear.

Further analysis showed that different members in the same miRNA family present similar expression profiles, except in a few stages (Figure 5), while the expression patterns between different miRNA families varied. In the study of peanut [31], the same results were also concluded. Two members of the ahy-miR159 family were similar and this may provide valuable information on the role that miRNAs play in plant growth [31].
MiRNA cluster analysis showed that members of a given cluster have parallel expression patterns, which implies that miRNA cluster members coordinately regulate fruit development. It was noticeable that different clusters contained quite similar miRNAs while the locations of clusters varied. The phenomenon suggests that those miRNAs are always transcribed together and may be transcribed from different chromosomes or different segments on the same chromosome. A similar phenomenon has been previously reported [44]. The mir-3 to mir- 6 genes were clustered and showed high similarity in expression profiles [45].

\section{Target gene analysis of miRNAs in pear fruit}

MicroRNA regulates gene expression through inhibiting translation or degrading mRNA at a certain site [46]. Currently, bioinformatics methods have been used to decipher target genes in several studies $[47,48]$. To better understand the roles pear miRNAs play in fruit development, PickPlantTar was used to predict potential miRNA target genes by using the most abundant mature miRNA as queries. By a stringent criteria described in the methodology, 2,216 targets for 188 known miRNAs and 1,127 targets for 184 novel miRNAs with differential expression patterns were predicted (Additional file 6). The number of putative target genes for each conserved miRNA varied from 1 to 226. As showed in Figure 6, more than $50 \mathrm{miR}$ NAs targeted 4 to 10 genes. Thirty-three miRNAs had only one target gene, which may suggest a unique regulatory function played by these miRNAs. Meanwhile, we found that 4 miRNAs had more than 100 predicted target genes. For instance, miR396b targeted 226 genes, the highest among the known miRNAs, followed by miR5564 and miR4993 with 149 and 137 target gene numbers, respectively, which might indicate the wide regulation functions of these miRNAs. In addition, as suggested by Bonnet et al. [49], highly repetitive motifs corresponding to the miRNA sequence may contribute to the ubiquity of target genes, which means the possibility of the potential false prediction. Further experiments are needed to confirm the accurate function for these miRNAs.

The 2,216 targets for 188 known miRNAs are predicted to be implicated in a broad range of physiological or biochemical processes. All annotated targets were BLASTX searched against the protein database, followed by Gene Ontology (GO) analysis to assess the genes' putative functions. GO analysis contained three ontologies: biological process, cellular component, molecular function [50]. Shown as results of Figure 7, 18 categories in biological process were classified by the genes, followed by 9 categories for cellular component and molecular function, respectively. As metabolic processes are the most active process in fruit development, it is understandable that cellular processes and metabolic processes 


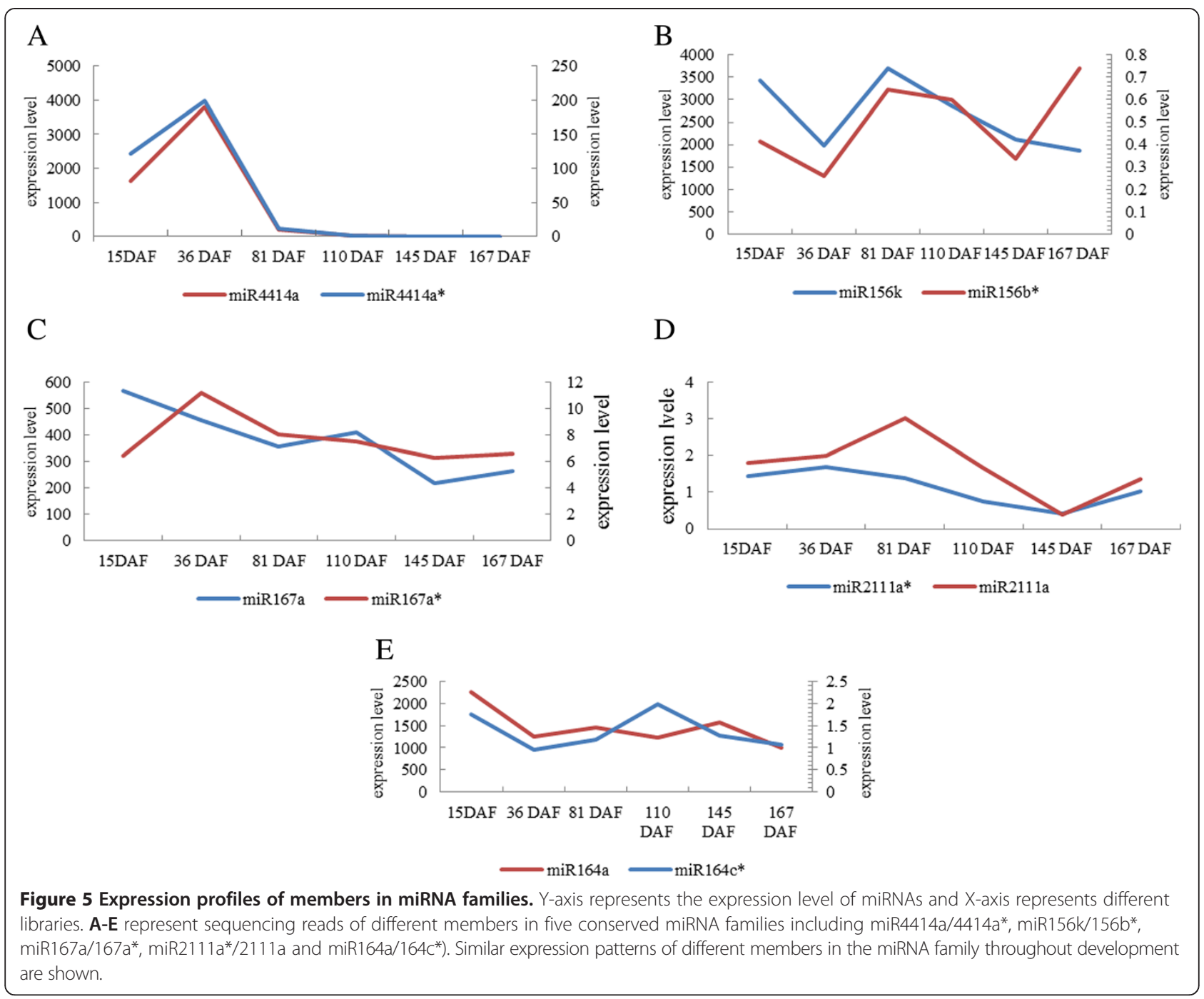

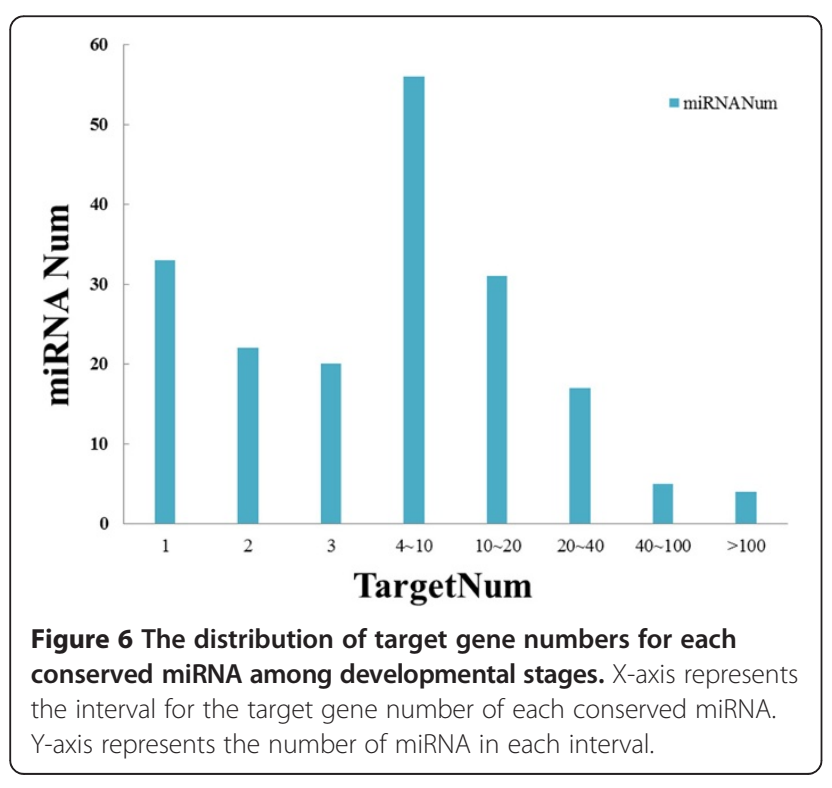

were the top two GO terms within biological processes. On the side of molecular function, the binding term and catalytic activity term occupied the largest numbers of genes. The result may suggest that miRNAs play key roles in regulation of substance metabolism because enzymes are indispensable catalysts for fruit development.

\section{MiRNAs regulate pear fruit development}

The development of pear fruit is a complex process, as major changes are involved in various metabolic pathways [51]. In order to uncover the role of miRNA in regulating the fruit growth and maturity, the target genes of miRNAs were identified by Kyoto Encyclopedia of Genes and Genomes (KEGG) pathways according to the $P$-value and enrichment factor. A total of 254 pathways were illustrated as a result of a BLAST search against the KEGG database (Additional file 7). Screening by the criteria described in the methods, we assessed GO terms ordered by the enrichment factor (Figure 8). 


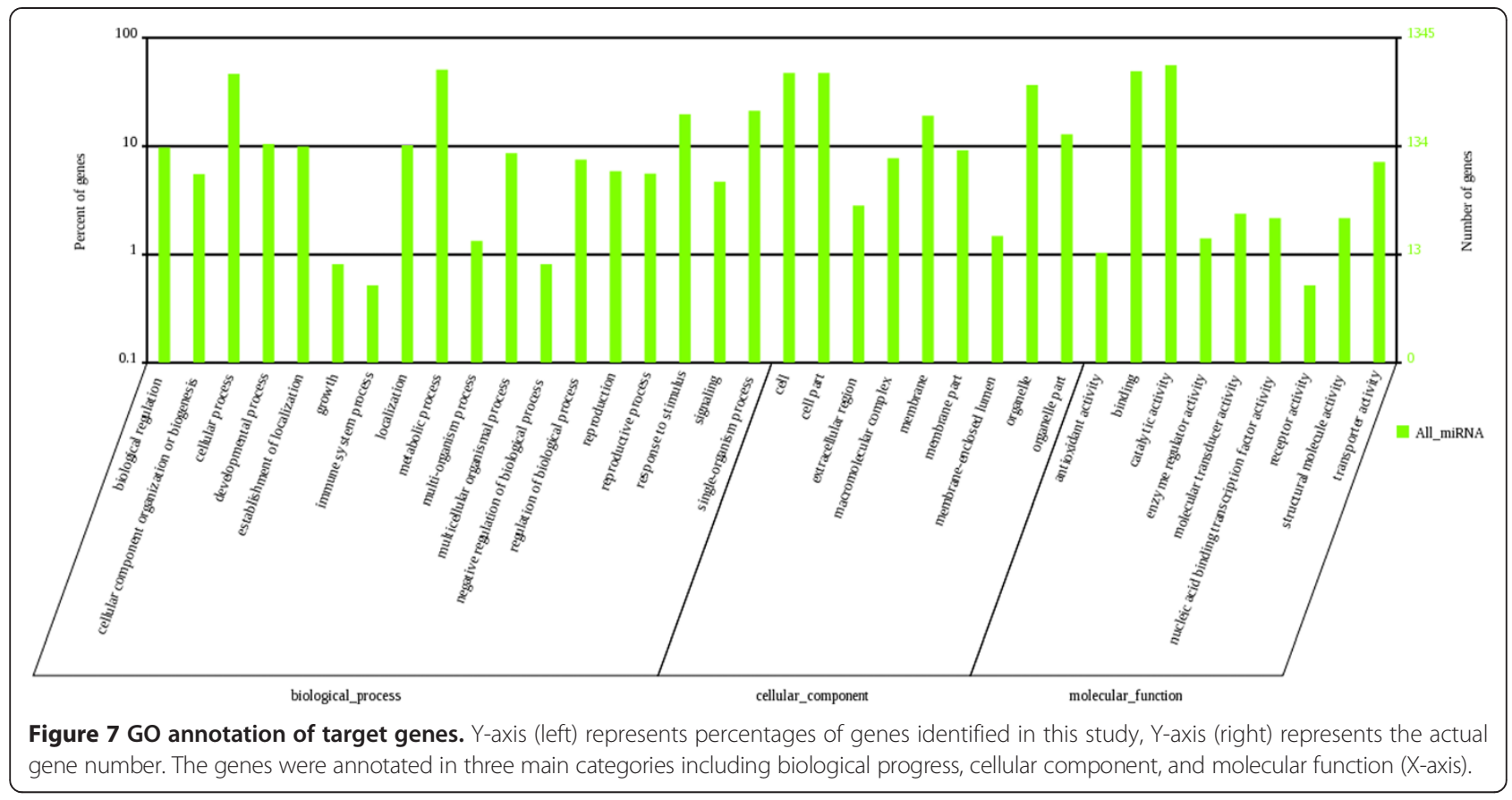

In the category of molecular function, the ATPase activity had the highest GO enrichment factor, 7.87470.

It can be concluded (Table 2) that the targets of conserved miRNAs are involved in all parts of plant development, from plant hormone signal transduction (Pbr042396.1) to plant pathogen interaction (Pbr041100.1). Besides the universal target genes such as ARF and UDP-sugar phrophosphorylase, unusual targets were also identified. The first class of targets suggested that the miRNAs take part in basic pear fruit metabolism, while the second class of targets showed the species-specific role played by miRNAs in pear fruit.

When we further explored the relationship of some miRNAs and their putative target genes (RNAseq data from pear genome project [23]), it was found that an opposite expression pattern presented in different stages of fruit development (Figure 9), such as miR397a, miR1132, miR5077 and miR396b, which suggested miRNAs were involved in lignin, sugar and acid pathways of fruit development. Hence, we took a deeper look at the miRNAs identified that are involved in several important pear fruit development metabolic pathways, including lignin pathway, sugar and acid pathway, hormone signaling and carbohydrate metabolism activities.

\section{Putative miRNAs related with pear fruit lignin pathway}

Stone cells are one of the important features of fruit quality in pear, rarely seen in other fresh fruit. As the primary component of stone cells, lignin synthesis has direct impact on their production. Lignin is an aromatic heteropolymer derived from phenylpropanoid [52]. Previously, there were reports that lignin may improve plant resistance to pathogens to a certain degree [53]. In Zinnia [54], the CCoAOMT is involved in the alternative methylation pathway in lignin biosynthesis. In Arabidopsis [55], overexpression of SND1, a NAC domain transcription factor, results in activation of the biosynthetic genes for secondary wall. In pear, Wu et al. reported 66 lignin synthesis-related gene families and depicted their pathways [23]. The RNA-seq data for these genes showed that they are highly expressed in the early stages, almost 10 -fold higher than near ripening.

In poplar, it has been demonstrated that overexpressed Corngrass 1 miRNA, belonging to the miR156 family, in the transgenic poplar plant 35S:Cg1 has dramatic effects on plant architecture and stem lignin content [56]. The induction of miR828 in sweet potato may regulate the phenylpropanoid pathway and biosynthesis of lignin by repressing the expression of IbMYB and IbTLD [57].

Through GO annotation of the target genes and comparison with KEGG database, six miRNAs (miR397a, miR395a, miR408, miR2936, miR408b*, and miR3627) among the twelve down-regulated miRNAs were shown involving in metabolic pathway and biosynthesis of secondary metabolites comprising the lignin synthesis pathway (Figure 10). Among them, 27 target genes of miR397a were shown to be the most significant miRNAs involved in the lignin pathway. These genes (Table 3) were the homologs of Ptr-lac or Ath-lac. The laccase-like enzyme could catalyze coniferyl alcohol polymerization, implicating laccases in lignification [52]. The transcripts per million (TPM) value for miR397a showed a decrease in the development periods, consistent with the role of pear fruit 


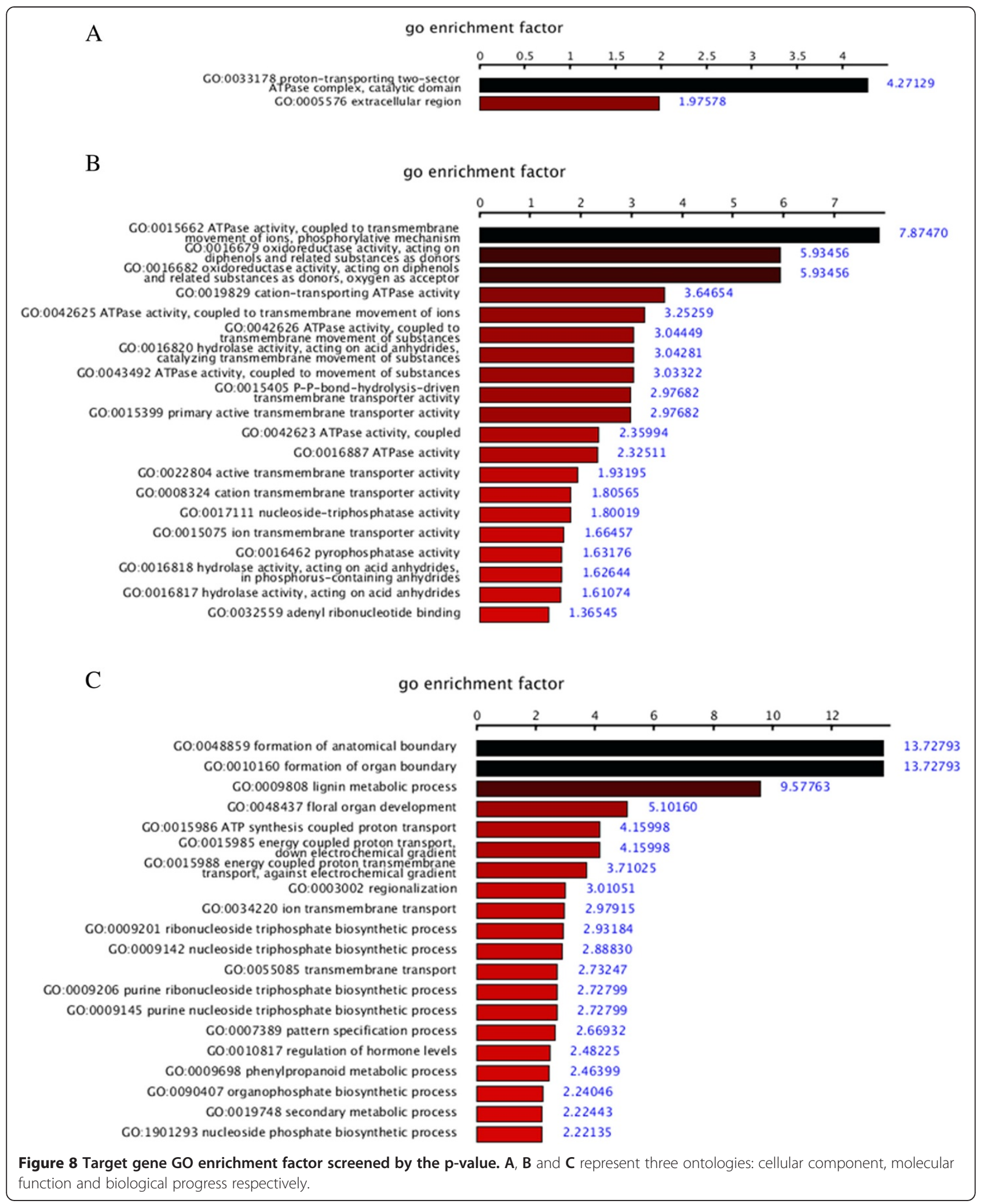

lignin synthesis showed by $\mathrm{Wu}$ et al. [23], while the transcription of several targets showed the opposite tendency from miR397a (Figure 9).
The conclusion was consistent with the research in Populus trichocarpa [58]. Twenty-nine laccase genes were predicted to be targets of ptr-miR397a [59]. By 
Table 2 Target genes of conserved miRNAs (excerpted*)

\begin{tabular}{|c|c|c|}
\hline microRNA & Target gene ID & Gene annotation/pathway ( $p$-value) \\
\hline \multirow[t]{19}{*}{ miR1061-3p } & Pbr041100.1 & Plant-pathogen interaction(7.190677e-06) \\
\hline & Pbr025269.1 & Plant-pathogen interaction(7.190677e-06) \\
\hline & Pbr019706.1 & Plant-pathogen interaction(7.190677e-06) \\
\hline & Pbr014433.1 & Plant-pathogen interaction(7.190677e-06) \\
\hline & Pbr010237.1 & Plant hormone signal transduction(0.01510044) Plant-pathogen interaction(7.190677e-06) \\
\hline & Pbr002521.1 & Plant hormone signal transduction(0.01510044) Plant-pathogen interaction(7.190677e-06) \\
\hline & Pbr029017.1 & $\begin{array}{l}\text { Phenylalanine, tyrosine and tryptophan biosynthesis(1.488743e-06) Metabolic pathways(0.7902142) } \\
\text { Other glycan degradation(0.855243) Fructose and mannose metabolism(0.6615606) Glycosphingolipid } \\
\text { biosynthesis - ganglio series(0.5541742) Sphingolipid metabolism(0.1582752) Lysosome(0.9793836) } \\
\text { Amino sugar and nucleotide sugar metabolism(0.6427769) Glycosaminoglycan degradation }(0.4927528) \\
\text { Ribosome(0.987106) Galactose metabolism(0.2583273) Biosynthesis of secondary metabolites( } 0.9498542)\end{array}$ \\
\hline & Pbr031602.1 & Mineral absorption(0.00709937) \\
\hline & Pbr029046.1 & Mineral absorption(0.00709937) \\
\hline & Pbr021467.1 & Mineral absorption(0.00709937) \\
\hline & Pbr002476.1 & Mineral absorption(0.00709937) \\
\hline & Pbr012616.2 & $\begin{array}{l}\text { Metabolic pathways(0.7902142) Folate biosynthesis(0.1157641) ABC transporters(0.06561596) Arginine } \\
\text { and proline metabolism(0.1871821) GABAergic synapse(0.9817247) Nitrogen metabolism(0.5698157) } \\
\text { Polyketide sugar unit biosynthesis(0.3271947) Alanine, aspartate and glutamate metabolism(0.9892745) } \\
\text { Glyoxylate and dicarboxylate metabolism(0.9626975) Glutamatergic synapse(0.9998555) Streptomycin } \\
\text { biosynthesis(0.5326464) Microbial metabolism in diverse environments(0.9297261) Biosynthesis of } \\
\text { secondary metabolites(0.9498542) Two-component system(0.2053418) }\end{array}$ \\
\hline & Pbr021166.1 & $\begin{array}{l}\text { Influenza A(0.2265907) Tuberculosis(0.08865112) Leishmaniasis }(0.04564140) \text { Chagas disease (American } \\
\text { trypanosomiasis)(0.02067325) Plant-pathogen interaction(7.190677e-06) Toxoplasmosis }(0.2633427) \\
\text { Toll-like receptor signaling pathway(0.05315244) Neurotrophin signaling pathway }(0.05126187) \\
\text { Apoptosis(0.06810953) NF-kappa B signaling pathway(0.073712) Measles }(0.06773311) \text { Pertussis( } 0.03473645)\end{array}$ \\
\hline & Pbr040822.1 & $\begin{array}{l}\text { Flavonoid biosynthesis(0.599654) Metabolic pathways(0.7902142) Biosynthesis of secondary } \\
\text { metabolites(0.9498542) }\end{array}$ \\
\hline & Pbr040817.1 & $\begin{array}{l}\text { Flavonoid biosynthesis( } 0.599654) \text { Metabolic pathways(0.7902142) Biosynthesis of secondary } \\
\text { metabolites(0.9498542) }\end{array}$ \\
\hline & Pbr021205.1 & $\begin{array}{l}\text { Ethylbenzene degradation(0.369114) Leishmaniasis(0.04564140) Chagas disease (American } \\
\text { trypanosomiasis)(0.02067325) Plant-pathogen interaction(7.190677e-06) Toxoplasmosis(0.2633427) } \\
\text { Neurotrophin signaling pathway(0.05126187) Microbial metabolism in diverse environments( } 0.9297261) \\
\text { NF-kappa B signaling pathway(0.073712) Measles(0.06773311) Tyrosine metabolism(0.3092827) } \\
\text { Influenza A(0.2265907) Aminobenzoate degradation(0.3980524) Tuberculosis( } 0.08865112) \text { Metabolic } \\
\text { pathways( }(0.7902142) \text { Fructose and mannose metabolism(0.6615606) Limonene and pinene } \\
\text { degradation(0.656067) Benzoate degradation(0.3951967) Toll-like receptor signaling pathway } \\
(0.05315244) \text { Apoptosis(0.06810953) Pertussis( } 0.03473645) \text { Pyrimidine metabolism(0.0004838167) }\end{array}$ \\
\hline & Pbr035730.1 & $\begin{array}{l}\text { Cytosolic DNA-sensing pathway(6.107676e-13) Metabolic pathways(0.7902142) Plant-pathogen } \\
\text { interaction(7.190677e-06) RNA polymerase(1.034169e-09) Pyrimidine metabolism(0.0004838167) } \\
\text { Epstein-Barr virus infection(8.479755e-05) Huntington's disease(8.38133e-08) Purine metabolism } \\
(0.0001980336)\end{array}$ \\
\hline & Pbr010706.1 & $\begin{array}{l}\text { Circadian rhythm - mammal(0.3646747) Wnt signaling pathway(0.3688827) Protein processing } \\
\text { in endoplasmic reticulum(0.9999496) TGF-beta signaling pathway(0.9755566) Ubiquitin mediated } \\
\text { proteolysis( }(0.321184) \text { Oocyte meiosis(0.9154166) Cell cycle(0.9997656) Cell cycle - yeast(0.5227999) } \\
\text { Herpes simplex infection(0.9478489) }\end{array}$ \\
\hline & Pbr026497.1 & Cell cycle - yeast(0.5227999) \\
\hline $\operatorname{miR} 1121$ & Pbr018590.1 & Metabolic pathways(0.7902142) Glycosylphosphatidylinositol(GPI)-anchor biosynthesis(0.1935023) \\
\hline \multirow[t]{3}{*}{$\operatorname{miR} 1318$} & Pbr027745.1 & $\begin{array}{l}\text { Valine, leucine and isoleucine degradation( } 0.853519) \text { Propanoate metabolism( } 0.7921382) \text { Metabolic } \\
\text { pathways(0.7902142) Lysine biosynthesis(0.3398862) Glycine, serine and threonine metabolism } \\
(0.8336738) \text { Tryptophan metabolism( } 0.4881696) \text { Arginine and proline metabolism(0.1871821) Pyruvate } \\
\text { metabolism( } 0.9296067) \text { Glycolysis / Gluconeogenesis( } 0.9894463) \text { beta-Alanine metabolism(0.8613309) } \\
\text { Fatty acid metabolism(0.830646) Histidine metabolism( }(0.8285719) \text { Glycerolipid metabolism(0.707723) } \\
\text { Lysine degradation(0.3979612) Biosynthesis of secondary metabolites(0.9498542) Ascorbate and } \\
\text { aldarate metabolism( }(9.178918 \mathrm{e}-07)\end{array}$ \\
\hline & Pbr009875.1 & Spliceosome(0.338066) \\
\hline & Pbr020008.1 & Regulation of autophagy(0.2863020) \\
\hline
\end{tabular}


Table 2 Target genes of conserved miRNAs (excerpted*) (Continued)

\begin{tabular}{|c|c|c|}
\hline & Pbr013669.1 & Plant-pathogen interaction(7.190677e-06) \\
\hline & Pbr009166.1 & Plant hormone signal transduction(0.01510044) \\
\hline & Pbr036152.1 & $\begin{array}{l}\text { Phenylpropanoid biosynthesis(0.1081946) Metabolic pathways(0.7902142) Biosynthesis of } \\
\text { secondary metabolites( } 0.9498542) \text { Phenylalanine metabolism( } 0.1547410)\end{array}$ \\
\hline & Pbr038845.1 & $\begin{array}{l}\text { Naphthalene degradation(0.930259) Aminobenzoate degradation(0.3980524) Chloroalkane } \\
\text { and chloroalkene degradation(0.9450628) Polycyclic aromatic hydrocarbon degradation } \\
(0.4501106) \text { Microbial metabolism in diverse environments(0.9297261) Bisphenol degradation } \\
\text { (0.8789056) Limonene and pinene degradation(0.656067) Biosynthesis of secondary } \\
\text { metabolites(0.9498542) }\end{array}$ \\
\hline & Pbr015038.1 & $\begin{array}{l}\text { Metabolic pathways }(0.7902142) \text { Citrate cycle (TCA cycle)(0.997454) Microbial metabolism in } \\
\text { diverse environments( } 0.9297261) \text { Biosynthesis of secondary metabolites }(0.9498542)\end{array}$ \\
\hline & Pbr031471.1 & GABAergic synapse $(0.9817247)$ \\
\hline & Pbr013295.1 & Circadian rhythm - plant(0.924008) \\
\hline & Pbr026842.1 & $\begin{array}{l}\text { Alanine, aspartate and glutamate metabolism(0.9892745) Bacterial secretion system(0.8448431) } \\
\text { Metabolic pathways(0.7902142) Protein export(0.6659996) Pyrimidine metabolism(0.0004838167) }\end{array}$ \\
\hline & Pbr004124.1 & $\begin{array}{l}\text { Alanine, aspartate and glutamate metabolism(0.9892745) Bacterial secretion system }(0.8448431) \\
\text { Metabolic pathways }(0.7902142) \text { Protein export }(0.6659996) \text { Pyrimidine metabolism(0.0004838167) }\end{array}$ \\
\hline \multirow[t]{8}{*}{ miR160a } & Pbr042396.1 & Plant hormone signal transduction $(0.01510044)$ \\
\hline & Pbr039066.1 & Plant hormone signal transduction(0.01510044) \\
\hline & Pbr037271.1 & Plant hormone signal transduction(0.01510044) \\
\hline & Pbr016467.1 & Plant hormone signal transduction(0.01510044) \\
\hline & Pbr008550.1 & Plant hormone signal transduction( 0.01510044$)$ \\
\hline & Pbr008404.1 & Plant hormone signal transduction(0.01510044) \\
\hline & Pbr008352.1 & Plant hormone signal transduction $(0.01510044)$ \\
\hline & Pbr008195.1 & Plant hormone signal transduction(0.01510044) \\
\hline
\end{tabular}

*More target genes of all miRNAs are listed in Additional file 6.
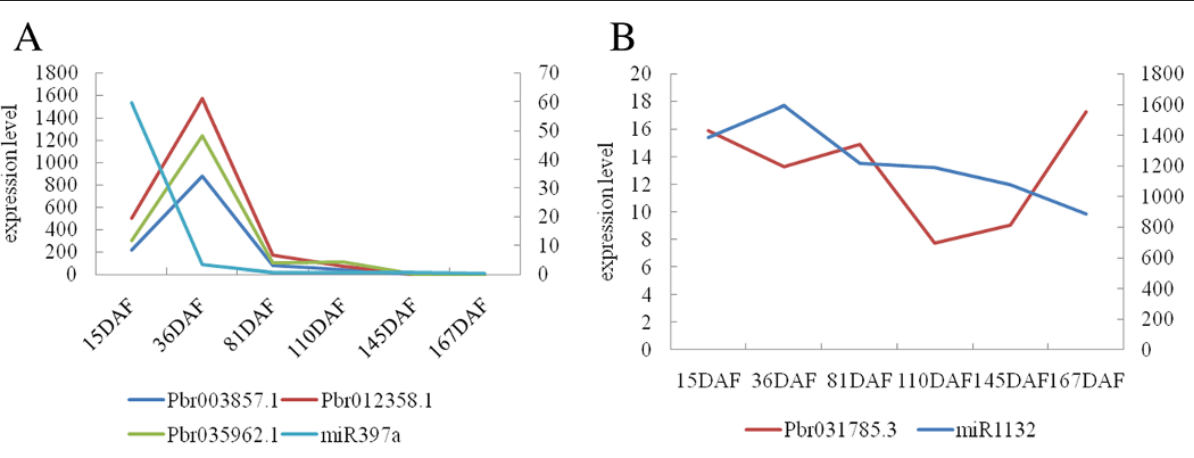

15DAF 36DAF 81DAF 110DAF145DAF167DAF

- Pbr031785.3 - miR1132

$\mathrm{D}$

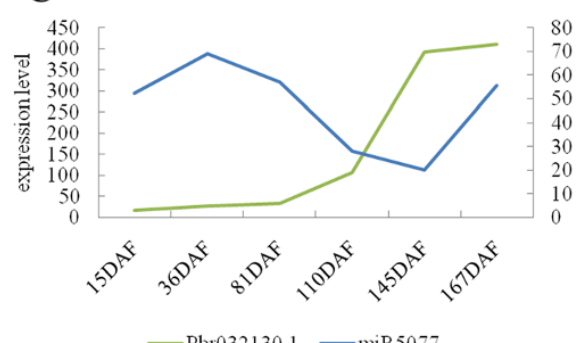

Figure 9 Expression pattern of miRNAs and target genes. A, B, C, and D represent the comparisons of the expression patterns during pear fruit development for miR397a, miR1132, miR5077 and miR396b and their putative target genes, respectively. Y-axis (left) represents expression level of target genes, Y-axis (right) represents the expression level of miRNAs. 


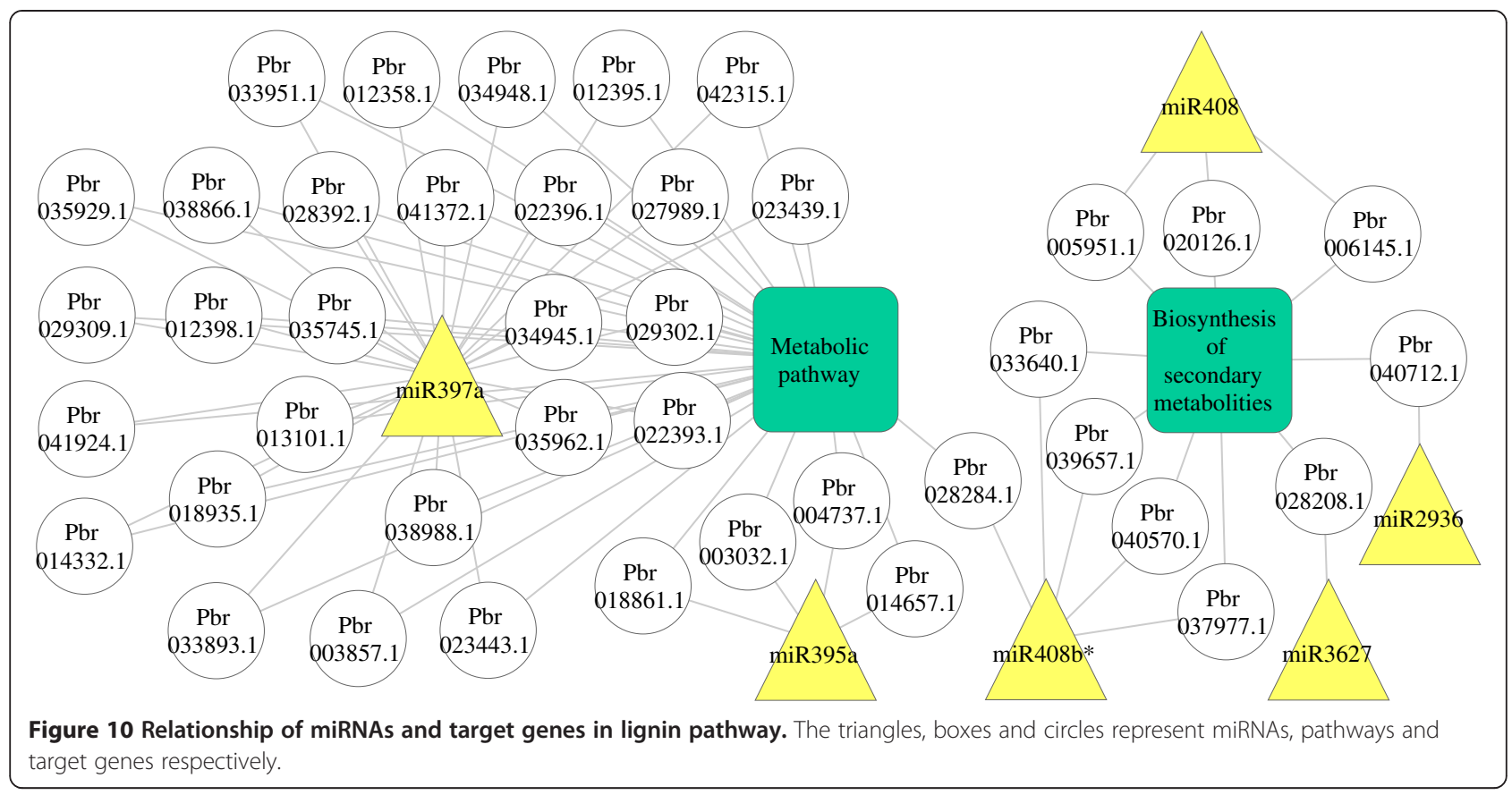

over expression of Ptr-miR397a in the transgenic lines, 17 PtrLACs were down-regulated, which resulted in a $\sim 40 \%$ decreasing of the total laccase activity, and lignin content was also reduced. The transcriptome-based gene expression implicated the ptr-miR397a and lac in co-regulating lignin biosynthesis in wood formation. The detailed function of miR397a in pear fruit lignification still needs further studies and confirmed biological experiments.

Besides the miRNAs with significant differential expression, several other miRNAs were also analyzed according to their target gene annotation. MiR3711, miR419, and miR5260 targeted the hydroxycinnamoyl transferase (HCT) gene, which is known to promote lignin synthesis [60]. According to analysis in the pear genome [23], HCT gene is one of the pivotal genes in synthesis of lignin in pear fruit, leading to high levels of conversion of p-coumaroyl$\mathrm{CoA}\left(\mathrm{C} 3^{\prime} \mathrm{H}\right)$ into caffeoyl-Coa (PCC) and feruloyl-CoA (FC). Another two key genes analyzed in lignin synthesis peroxidase (POD) and 4CL, are putatively targeted by miR5021 and miR396b, respectively.

\section{Putative miRNAs related with pear fruit sugar and acid pathway}

Pear fruit quality and flavor are largely impacted by the composition and content of sugar and acid, thus metabolism of sugar and acid is one of the most significant fruit development characteristics. KEGG pathway analysis showed 24 sugar and acid pathways in pear fruit development, such as fructose and mannose metabolism, galactose metabolism, carbon fixation in photosynthetic organisms, glycolysis/gluconeogenesis, and biosynthesis of secondary metabolites. By the annotation of targets, nine miRNAs were identified as related to genes taking part in the above pathways. As listed in Table 3, these include Malate PEPCK-ATP (Pbr031785.3, Pbr038213.1), Citrate Acly(Pbr015038.1), Malate Malt (Pbr020930.1, Pbr023085.1, Pbr010337.1, Pbr016769.1, Pbr016770.1).

From the differentially expressed miRNAs (Additional file 5), several miRNAs have higher expression level in early phases than in mature phases. In early development phases, miR4414a* showed higher TPM (121.5524 in 15DAF and 198.7602 in 36DAF). When the fruit reached the mature phase, the TPM gradually decreased (10.8494 in 81DAF, 0.7175 in 110DAF, 0.1273 in 145DAF, and 0.1649 in 167DAF). Dihydrolipoyl transacetylase (or $E_{2}$, Pbr015262.1) was suggested to be the putative target of miR4414a*. $E_{2}$ is one of the main enzymes of Tricarboxylic acid cycle (TAC) [61], which is known for its wide role in many pivotal plant metabolism pathways.

\section{Putative miRNAs regulated other pear fruit development genes}

The majority of miRNA molecules chosen for this study and the complementary sites within their target genes display a high degree of conservation between species. Thus, the pear genome database was examined for the presence of potential miRNA targets. Auxin response factor (ARF), a transcription factors, regulates auxin signal transduction during plant growth. Niu et al. [24] previously reported putative orthologs of ARF transcription factors as targets of pear miR160 family. In our study, the same result was identified. MiR160a potentially targets ARF16, ARF17 and ARF18. As a companion, miR167 was identified to 
Table 3 MiRNAs and target genes involved in lignification and sugar and acid pathways

\begin{tabular}{|c|c|c|c|}
\hline miRNA name & Target gene ID & Target gene description & Pathway \\
\hline \multirow[t]{27}{*}{ miR397a } & Pbr003857.1 & Laccase & Metabolic pathways(0.7902142) \\
\hline & Pbr012358.1 & & Metabolic pathways(0.7902142) \\
\hline & Pbr012395.1 & & Metabolic pathways(0.7902142) \\
\hline & Pbr012398.1 & & Metabolic pathways(0.7902142) \\
\hline & Pbr013101.1 & & Metabolic pathways(0.7902142) \\
\hline & Pbr014332.1 & & Metabolic pathways(0.7902142) \\
\hline & Pbr018935.1 & & Metabolic pathways(0.7902142) \\
\hline & Pbr022393.1 & & Metabolic pathways(0.7902142) \\
\hline & Pbr022396.1 & & Metabolic pathways(0.7902142) \\
\hline & Pbr023439.1 & & Metabolic pathways(0.7902142) \\
\hline & Pbr023443.1 & & Metabolic pathways(0.7902142) \\
\hline & Pbr027989.1 & & Metabolic pathways(0.7902142) \\
\hline & Pbr028392.1 & & Metabolic pathways(0.7902142) \\
\hline & Pbr029302.1 & & Metabolic pathways(0.7902142) \\
\hline & Pbr029309.1 & & Metabolic pathways(0.7902142) \\
\hline & Pbr033893.1 & & Metabolic pathways(0.7902142) \\
\hline & Pbr033951.1 & & Metabolic pathways(0.7902142) \\
\hline & Pbr034945.1 & & Metabolic pathways(0.7902142) \\
\hline & Pbr034948.1 & & Metabolic pathways(0.7902142) \\
\hline & Pbr035745.1 & & Metabolic pathways(0.7902142) \\
\hline & Pbr035929.1 & & Metabolic pathways(0.7902142) \\
\hline & Pbr035962.1 & & Metabolic pathways(0.7902142) \\
\hline & Pbr038866.1 & & Metabolic pathways(0.7902142) \\
\hline & Pbr038988.1 & & Metabolic pathways(0.7902142) \\
\hline & Pbr041372.1 & & Metabolic pathways(0.7902142) \\
\hline & Pbr041924.1 & & Metabolic pathways(0.7902142) \\
\hline & Pbr042315.1 & & Metabolic pathways(0.7902142) \\
\hline miR1132 & Pbr031785.3 & Malate_PEPCK_PEPCK-ATP & \\
\hline $\operatorname{miR} 1318$ & Pbr015038.1 & Citrate_ACL_ACLY & $\begin{array}{l}\text { Metabolic pathways( } 0.7902142) \text {,Microbial metabolism in diverse } \\
\text { environments( } 0.9297261), \text { Biosynthesis of secondary metabolites } \\
(0.9498542) \text {,Citrate cycle (TCA cycle)(0.997454) }\end{array}$ \\
\hline miR2635 & Pbr038213.1 & Malate_PEPC_PEPC & $\begin{array}{l}\text { Carbon fixation in photosynthetic organisms(0.7361554),Metabolic } \\
\text { pathways(0.7902142),Methane metabolism(0.9082858),Pyruvate } \\
\text { metabolism(0.9296067),Microbial metabolism in diverse environments } \\
(0.9297261), \text { Carbon fixation pathways in prokaryotes(0.9871138) }\end{array}$ \\
\hline \multirow[t]{2}{*}{ miR394a } & Pbr020930.1 & Malate_MalT & \\
\hline & Pbr023085.1 & Malate_MalT & \\
\hline \multirow[t]{4}{*}{ miR396b } & Pbr006726.1 & DNA_G6PDH_G6PDH & $\begin{array}{l}\text { Metabolic pathways(0.7902142),Microbial metabolism in diverse } \\
\text { environments(0.9297261),Biosynthesis of secondary metabolites } \\
\text { (0.9498542),Pentose phosphate pathway(0.975254),Glutathione } \\
\text { metabolism(0.9974516) }\end{array}$ \\
\hline & Pbr010337.1 & Malate_MalT & \\
\hline & Pbr016769.1 & Malate_MalT & \\
\hline & Pbr016770.1 & Malate_MalT & \\
\hline \multirow[t]{3}{*}{ miR5077 } & Pbr023965.1 & Sugar_HT & \\
\hline & Pbr032130.1 & Sugar_HT & Meiosis - yeast $(0.9924183)$ \\
\hline & Pbr033292.1 & Sugar_HT & \\
\hline
\end{tabular}




\section{Table 3 MiRNAs and target genes involved in lignification and sugar and acid pathways (Continued)}

\begin{tabular}{|c|c|c|c|}
\hline miR5500 & Pbr029752.1 & Sugar_HK_HK & $\begin{array}{l}\text { Galactose metabolism(0.2583273),Butirosin and neomycin } \\
\text { biosynthesis(0.4998806),Streptomycin biosynthesis(0.5326464), } \\
\text { Amino sugar and nucleotide sugar metabolism(0.6427769), } \\
\text { Fructose and mannose metabolism(0.6615606),Metabolic } \\
\text { pathways(0.7902142),Insulin signaling pathway(0.878923), } \\
\text { Carbohydrate digestion and absorption(0.919634),Microbial } \\
\text { metabolism in diverse environments(0.9297261),Biosynthesis } \\
\text { of secondary metabolites(0.9498542),Starch and sucrose } \\
\text { metabolism(0.9606751),Glycolysis / Gluconeogenesis(0.9894463), } \\
\text { Type II diabetes mellitus(0.9906034) }\end{array}$ \\
\hline $\operatorname{miR} 825^{*}$ & Pbr016798.1 & Sugar_ALD-ALD1 & $\begin{array}{l}\text { Phenylalanine, tyrosine and tryptophan biosynthesis(1.488743e-06), } \\
\text { Sulfur metabolism(0.04454147),Fructose and mannose metabolism } \\
\text { (0.6615606),Carbon fixation in photosynthetic organisms(0.7361554), } \\
\text { Metabolic pathways(0.7902142),Cysteine and methionine metabolism } \\
\text { (0.9034785),Microbial metabolism in diverse environments(0.9297261), } \\
\text { Biosynthesis of secondary metabolites(0.9498542),Pentose phosphate } \\
\text { pathway(0.975254),Glycolysis / Gluconeogenesis(0.9894463) }\end{array}$ \\
\hline \multirow[t]{3}{*}{ miR952b } & Pbr012392.1 & Sugar_F16BP_F16BP1 & $\begin{array}{l}\text { Fructose and mannose metabolism(0.6615606),Carbon fixation in } \\
\text { photosynthetic organisms(0.7361554),Metabolic pathways(0.7902142), } \\
\text { Insulin signaling pathway(0.878923),Methane metabolism(0.9082858), } \\
\text { Microbial metabolism in diverse environments(0.9297261),Biosynthesis } \\
\text { of secondary metabolites(0.9498542),Pentose phosphate pathway } \\
\text { (0.975254),Glycolysis / Gluconeogenesis(0.9894463) }\end{array}$ \\
\hline & Pbr012401.1 & Sugar_F16BP_F16BP1 & $\begin{array}{l}\text { Fructose and mannose metabolism(0.6615606),Carbon fixation in } \\
\text { photosynthetic organisms(0.7361554),Metabolic pathways(0.7902142), } \\
\text { Insulin signaling pathway(0.878923),Methane metabolism(0.9082858), } \\
\text { Microbial metabolism in diverse environments(0.9297261),Biosynthesis } \\
\text { of secondary metabolites(0.9498542),Pentose phosphate pathway } \\
\text { (0.975254),Glycolysis / Gluconeogenesis(0.9894463) }\end{array}$ \\
\hline & Pbr035932.1 & Sugar_F16BP_F16BP1 & $\begin{array}{l}\text { Fructose and mannose metabolism(0.6615606),Carbon fixation in } \\
\text { photosynthetic organisms(0.7361554),Metabolic pathways(0.7902142), } \\
\text { Insulin signaling pathway(0.878923),Methane metabolism(0.9082858), } \\
\text { Microbial metabolism in diverse environments(0.9297261),Biosynthesis } \\
\text { of secondary metabolites(0.9498542),Pentose phosphate pathway } \\
\text { (0.975254),Glycolysis / Gluconeogenesis(0.9894463) }\end{array}$ \\
\hline
\end{tabular}

target the hypothetical proteins LOC100242923 and LOC100265118. MiR160 and miR167 have been experimentally confirmed in several plant species including Arabidopsis thaliana [62] and soybean [63] that bind complementary sites in the UTR of ARF.

Known as a catalyzer of the conversion of various monosaccharide 1-phosphates to the respective UDPsugars, UDP-sugar phrophosphorylase was shown to be essential in pollen development in Arabidopsis [64], and was putatively targeted by miR782 in our analysis. While there have previously been rare reports about miR782, it is necessary to do further studies to confirm its function.

\section{Conclusion}

We identified 337 conserved miRNAs and 297 novel miRNAs for pear fruit at different developmental stages using the Illumina Hiseq2000 sequencing method. Through comparison with the pear genome, the transcript sites for these miRNAs were located. Fourteen miRNA clusters at $1 \mathrm{~kb}$ and 66 miRNA clusters at $10 \mathrm{~kb}$ were identified, respectively. Analysis of differential expression data suggested some roles for miRNAs in pear fruit development. Combined with target prediction and GO enrichment analysis, 2216 targets for 188 known miRNAs and 1,127 targets for 184 novel miRNAs were predicted and their functions shown. Several fruit development pathways were analyzed including lignin pathway, sugar and acid pathway, and hormone signaling. Combined with computational analysis and experimental confirmation, the research contributes valuable information for further functional research of microRNA in fruit development for pear and other species.

\section{Methods \\ Plant materials}

The fruits, 10-20 depending on the fruit size and period, of 'Dangshansu' were collected for each developmental stage $15,36,81,110,145$, and 167 days after flowering (DAF), from three different trees that were grown in the pear depository at Pukou District pomology farm of Nanjing Agriculture University. After washing and removing kernels, fruit samples in the same stage were mixed and ground together, then immediately frozen in liquid nitrogen and stored at $-80^{\circ} \mathrm{C}$ after collection. 


\section{RNA extraction and deep sequencing}

Total RNA was extracted from fruit samples using CTAB reagent according to the previously reported protocol by Chang et al. [65]. The concentration of RNA was measured by a NanoDrop 2000 spectrophotometer (NanoDrop Technologies, Wilmington, DE, USA) and visually ascertained with electrophoresis on a $1 \%$ agarose gel.

Six sRNA samples were constructed and sequenced by the Beijing Genomics Institute (BGI) (Shenzhen, Guangdong Province, China) using the Illumina HiSeq 2000 platform. The construction of the sRNA library consisted of the following steps: acrylamide gel purification of the RNA bands corresponding to a size range of $18-30 \mathrm{nt}$; ligation of the 3p and $5 \mathrm{p}$ adapters to the RNA in two subsequent steps, each followed by acrylamide gel purification; and a final step of PCR amplification to generate a cDNA colony template library for Illumina sequencing. The RNA-seq data used for the expression level of target genes was resourced from the published pear genome data which was available in the National Center for Biotechnology Information repository under accession PRJINA185970 (http://www.ncbi.nlm. nih.gov/bioproject/PRJNA185970).

\section{Bioinformatic analysis of miRNA identification}

After sequencing, raw sequencing reads were processed into clean reads. During this procedure, we filtered out low quality, adapter contaminative tags and discarded the remaining reads with lengths smaller than $18 \mathrm{nt}$. All unique clean reads, particularly the non-redundant reads, were considered for further analysis, such as non-coding RNA identification and annotation. First of all, rRNA, scRNA, snoRNA, snRNA, and tRNA of clean reads were identified by BLASTall search against the Rfam (version 10.1) database. Next, in order to determine conserved miRNA, clean reads were compared with known miRNAs of plants deposited at miRBase 19.0. Finally, the other sequences that did not map to known miRNAs and other kinds of small RNA were referred to as un-annotated sequences for novel miRNA prediction. We identified potentially novel miRNA by MIREAP, and predicted the secondary structure by RNAfold. The criteria used for selecting miRNA were based on Meyers et al. [66], such as mature miRNAs having $21 \mathrm{nt}$ bases in length and miRNA precursor sequences being able to fold into a hairpin secondary structure.

\section{Quantitative real-time PCR validation}

In order to confirm the sequencing results, qRT-PCR was applied to 6 miRNAs according to methods of previous research [67]. This method could not only confirm the existence of pear fruit miRNAs, but can also detect the expression level of miRNAs in various fruit development stages. Total RNA samples were sent to Oebiotech (Pudong district, Shanghai). The miScript II Reverse Transcription
Kit (Qiagen) was used for miRNA synthesis. Briefly, reactions were completed in a volume of $20 \mu \mathrm{L}$, containing RNA templates $1 \mu \mathrm{g} /$ Cone, $5 \times$ miScript HiSpec buffer $4 \mu \mathrm{L}$, $10 \times$ nucleics mix $2 \mu \mathrm{L}$, miScript reverse transcriptase mix $2 \mu \mathrm{L}$ and RNase free $\mathrm{H}_{2} \mathrm{O}$ up to $20 \mu \mathrm{L}$. The PCR conditions were performed in an ABI 9700 PCR system.

Based on the full miRNA sequences, the forward miRNA primers for real-time PCR were designed, with reverse primers the universal reverse primer for miRNA. The primer sequences are listed in Table 4. For each action, $1 \mu \mathrm{L}$ cDNA was mixed with $2 \times$ SYBRReal PreMix (Tiangen) $5 \mu \mathrm{L}$, forward primers and reverse primers $0.2 \mu \mathrm{L}(10 \mu \mathrm{M})$ respectively. Finally, RNase-free water was added up to the volume of $10 \mu \mathrm{L}$. PCR runs were $95^{\circ} \mathrm{C}$ for $10 \mathrm{~s}, 60^{\circ} \mathrm{C}$ for $30 \mathrm{~s}$ on the Roche LightCycler 480 IIPCR system. Each reaction was repeated three times. The miRNA expression was quantified using the comparative $\Delta \Delta C T$ method [68]. All expression results were normalised to expression levels in the stem. 5S rRNAs [69] was used as an internal control.

\section{Differential expression analysis}

The frequency of miRNAs in the two libraries was normalised to one million by the total number of miRNAs in each sample (transcripts per million (TPM) normalised expression $=$ initial miRNA count $* 1,000,000 /$ total count of clean reads). Following normalization, if the miRNA gene expression of two samples was zero, then it was revised to 0.01; if the miRNA gene expression of two samples was less than 1 , owing to their too low expression, they were not included in analysis of differential expression.

The fold-change between different days after flowering and 15DAF was calculated as: fold-change $=\log _{2}$ (treat/ 15DAF). The $p$-value was calculated using the formula below.

$$
p(x \mid y)=\left(\frac{N_{2}}{N_{1}}\right)^{y} \frac{(x+y) ! \quad C\left(y \leq y_{\min } \mid x\right)=\sum_{y-0}^{y \leq y_{\min }} p(y \mid x)}{x ! y !\left(1+\frac{N_{2}}{N_{1}}\right)^{(x+y+1)}} D\left(y \geq y_{\max } \mid x\right)=\sum_{y \geq y_{\max }}^{\infty} p(y \mid x)
$$

Table 4 qRT-PCR primer sequence list

\begin{tabular}{cl}
\hline miRNA name & Forward primer sequence* \\
\hline miR166a & TCGGACCAGGCTTCATTCCCC \\
miR4376-5p & ACGCAGGAGAGATGACGCCGA \\
miR156k & TTGACAGAAGAGAGTGAGCAC \\
miR396b-3p & TTCCACAGCTTTCTTGAACTG \\
miR164c* & TGGAGAAGCAGGGCACGTGCA \\
miR159b-3p & TGGATTGAAGGGAGCTCTACA \\
pear-5S & GAAAGATGCCAATTCATGCG \\
\hline
\end{tabular}

Note: *Reverse primers are universal reverse primers for miRNA. 


\section{Prediction of target genes}

The target genes for each miRNA were predicted as by the criteria of Allen et al. [70] and Schwab et al. [67], for miRNA targets of plants. Briefly, the criteria were as follows:

1) No more than four mismatches between miRNA and target (G-U bases count as 0.5 mismatches), 2) No more than two adjacent mismatches in the miRNA/target duplex, 3) No adjacent mismatches in positions 2-12 of the miRNA/target duplex (5' of miRNA), 4) No mismatches in positions 10-11 of miRNA/target duplex, 5) No more than 2.5 mismatches in positions $1-12$ of the miRNA/target duplex (5' of miRNA).

\section{GO enrichment and KEGG pathway analysis}

In order to further understand the functions of miRNA and their targets, GO enrichment and KEGG pathway analysis for all annotated miRNAs and their targets were performed. Blast2GO was employed to store information from the GO and KEGG pathway databases. All the sequences were identified by BLASTx searches against the GO protein database. A combined query was used in order to complete the GO annotation and pathway analysis against the GO and KEGG databases. Due to the large amount and complex branch structure of GO molecular functions, a significance threshold $P$-value was used to control the false discovery rate, referring to previous adjustment [71].

\section{Accession number}

Sequencing data obtained in this research have been submitted to the NCBI under the accession number PRJNA263308.

\section{Additional files}

Additional file 1: List of 362 conserved miRNA. Transcript site counts, sequences and length for 362 conserved miRNA.

Additional file 2: List of novel miRNA. Novel miRNAs identified in six libraries. For each library, A represents the novel miRNAs deposited in miRBase while $B$ represents all the novel miRNAs identified in the study. MiRNA family, miRNA ID, location, length, GC\%, MFE for precursor miRNA and count on $5 p$ and $3 p$ and total reads for mature miRNA are listed.

Additional file 3: Distribution of miRNAs on pear genome chromosomes. The distribution of miRNAs in six libraries on each pear chromosome.

Additional file 4: List of miRNAs cluster. 14 miRNA clusters at distances of $10 \mathrm{~kb}$ and 66 clusters at $100 \mathrm{~kb}$.

Additional file 5: Differential expression profiles of conserved miRNAs in six libraries. 15DAF is taken as control. The expression patterns of 362 conserved miRNA among the pear fruit development stages. With color closer to red, higher expression level is represented.

Additional file 6: List of miRNA target genes. A: Conserved and B: novel miRNA target genes.

Additional file 7: KEGG pathway annotation for all miRNA target genes. A total of 235 KEGG pathways of the target genes annotated in the study.

\section{Competing interests}

The authors declare that they have no competing interests.

\section{Authors' contributions}

JW and DFW contributed to the experiment design and management, data analysis and manuscript preparation. YFL and XQ participated in the data analyses. LW carried out the qRT-PCR experiments. JW and SLZ supervised the research. All authors read and approved the final manuscript.

\section{Acknowledgements}

This work was financially supported by National Natural Science Foundation of China (31230063, 31171928), the Jiangsu Province Science and Technology Support Funds (BE2011320), Ministry of education Program for New Century Excellent Talents in University (NCET-13-0864).

\section{Author details}

${ }^{1}$ College of Horticulture, State Key Laboratory of Crop Genetics and Germplasm Enhancement, Nanjing Agricultural University, Nanjing 210095, China. ${ }^{2}$ BGI-Shenzhen, Shenzhen 518083, China.

Received: 18 March 2014 Accepted: 23 October 2014

Published: 3 November 2014

\section{References}

1. Lee RC, Feinbaum RL, Ambros V: The C. elegans heterochronic gene lin-4 encodes small RNAs with antisense complementarity to lin-14. Cell 1993, 75(5):843-854.

2. Minju H, Narry Kim V: Regulation of microrna biogenesisi. Nat Rev Mol Cell Bio 2014, 15:509-524a.

3. Rogers $\mathrm{K}$, Chen $\mathrm{X}$ : Biogenesis, tumover, and mode of action of plant microRNAs. Plant Cell 2013, 25:2383-2399.

4. Debat HJ, Ducasse DA: Plant microRNAs: recent advances and future challenges. Plant Mol Biol Rep 2014, doi:10.1007/s11105-014-0727-z.

5. Reinhart BJ, Weinstein EG, Rhoades MW, Bartel B, Bartel DP: MicroRNAs in plants. Gene Dev 2002, 16(13):1616-1626.

6. Bartel B, Bartel DP: MicroRNAs: at the root of plant development? Plant Physiol 2003, 132(2):709-717.

7. Zhang B, Pan X, Cannon CH, Cobb GP, Anderson TA: Conservation and divergence of plant microRNA genes. Plant J 2006, 46(2):243-259.

8. Csukasi F, Donaire L, Casanal A, Martinez-Priego L, Botella MA, Medina-Escobar N, Llave C, Valpuesta V: Two strawberry miR159 family members display developmental-specific expression patterns in the fruit receptacle and cooperatively regulate Fa-GAMYB. New Phytol 2012, 195(1):47-57.

9. Johnson C, Kasprzewska A, Tennessen K, Fernandes J, Nan GL, Walbot V, Sundaresan V, Vance V, Bowman LH: Clusters and superclusters of phased small RNAs in the developing inflorescence of rice. Genome Res 2009, 19(8):1429-1440.

10. Li D, Wang L, Liu X, Cui D, Chen T, Zhang H, Jiang C, Xu C, Li P, Li S, Zhao L, Chen $\mathrm{H}$ : Deep sequencing of maize small RNAs reveals a diverse set of microRNA in dry and imbibed seeds. PLoS One 2013, 8(1):e55107.

11. Aukerman MJ, Sakai H: Regulation of flowering time and floral organ identity by a MicroRNA and its APETALA2-like target genes. The Plant cell 2003, 15(11):2730-2741.

12. Chen $X: A$ microRNA as a translational repressor of APETALA2 in Arabidopsis flower development. Sci Signal 2004, 303(5666):2022.

13. Lauter N, Kampani A, Carlson S, Goebel M, Moose SP: microRNA172 down-regulates glossy15 to promote vegetative phase change in maize. P Natl Acad Sci USA 2005, 102(26):9412-9417.

14. Mallory AC, Bartel DP, Bartel B: MicroRNA-directed regulation of Arabidopsis AUXIN RESPONSE FACTOR17 is essential for proper development and modulates expression of early auxin response genes. Plant Cell 2005, 17(5):1360-1375.

15. Millar AA, Gubler F: The Arabidopsis GAMYB-like genes, MYB33 and MYB65, are microRNA-regulated genes that redundantly facilitate anther development. Plant Cell 2005, 17(3):705-721.

16. Gao Z, Shi T, Luo X, Zhang Z, Zhuang W, Wang L: High-throughput sequencing of small RNAs and analysis of differentially expressed microRNAs associated with pistil development in Japanese apricot. BMC Genomics 2012, 13:371.

17. Zhu QH, Helliwell CA: Regulation of flowering time and floral patterning by miR172. J Exp Bot 2011, 62(2):487-495. 
18. Karlova R, van Haarst JC, Maliepaard C, van de Geest H, Bovy AG, Lammers M, Angenent GC, de Maagd RA: Identification of microRNA targets in tomato fruit development using high-throughput sequencing and degradome analysis. J Exp Bot 2013, 64(7):1863-1878.

19. Moxon S, Jing R, Szittya G, Schwach F, Rusholme Pilcher RL, Moulton V, Dalmay T: Deep sequencing of tomato short RNAs identifies microRNAs targeting genes involved in fruit ripening. Genome Res 2008, 18(10):1602-1609.

20. Silva G, Silva E, Silva-Azevedo M, Guivin M, Ramiro D, Figueiredo C, Carrer $H_{\text {, }}$ Peres L, Nogueira F: MicroRNA 156-targeted SPL/SBP box transcription factors regulated tomato ovary and fruit development. Plant J 2014, 78(4):604-618

21. Itaya A, Bundschuh $R$, Archual AJ, Joung JG, Fei Z, Dai X, Zhao PX, Tang Y, Nelson RS, Ding B: Small RNAs in tomato fruit and leaf development. Bba 2008, 1779(2):99-107.

22. Liu Y, Wang L, Chen D, Wu X, Huang D, Chen L, Li L, Deng X, Xu Q: Genome-wide comparison of microRNAs and heir targeted transcripts among leaf, flower and fruit of sweet orange. BMC Genomics 2014, 15:695

23. Wu J, Wang Z, Shi Z, Zhang S, Ming R, Zhu S, Khan MA, Tao S, Korban SS, Wang H, Chen NJ, Nishio T, Xu X, Cong L, Qi K, Huang X, Wang Y, Zhao X, Wu J, Deng C, Gou C, Zhou W, Yin H, Qin G, Sha Y, Tao Y, Chen H, Yang Y, Song $Y$, Zhan D, et al: The genome of the pear (Pyrus bretschneideri Rehd.). Genome Res 2013, 23(2):396-408

24. Niu Q, Qian M, Liu G, Yang F, Teng Y: A genome-wide identification and characterization of mircoRNAs and their targets in 'Suli' pear (Pyrus pyrifolia white pear group). Planta 2013, 238(6):1095-1112.

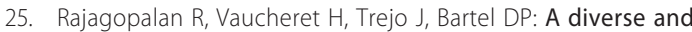
evolutionarily fluid set of microRNAs in Arabidopsis thaliana. Gene Dev 2006, 20(24):3407-3425.

26. Fahlgren N, Howell MD, Kasschau KD, Chapman EJ, Sullivan CM, Cumbie JS, Givan SA, Law TF, Grant SR, Dangl JL: High-throughput sequencing of Arabidopsis microRNAs: evidence for frequent birth and death of MIRNA genes. PLoS One 2007, 2(2):e219.

27. Song C, Wang C, Zhang C, Korir NK, Yu H, Ma Z, Fang J: Deep sequencing discovery of novel and conserved microRNAs in trifoliate orange (Citrus trifoliata). BMC Genomics 2010, 11(1):431.

28. Wang $T$, Chen $L$, Zhao $M$, Tian $Q$, Zhang $W-H$ : Identification of droughtresponsive microRNAs in Medicago truncatula by genome-wide highthroughput sequencing. BMC Genomics 2011, 12(1):367.

29. Szittya G, Moxon S, Santos DM, Jing R, Fevereiro MP, Moulton V, Dalmay T: High-throughput sequencing of Medicago truncatula short RNAs identifies eight new miRNA families. BMC Genomics 2008, 9(1):593.

30. Kou SJ, Wu XM, Liu Z, Liu YL, Xu Q, Guo WW: Selection and validation of suitable reference genes for miRNA expression normalization by quantitative RT-PCR in citrus somatic embryogenic and adult tissues. Plant Cell Rep 2012, 31(12):2151-2163.

31. Zhao CZ, Xia H, Frazier TP, Yao YY, Bi YP, Li AQ, Li MJ, Li CS, Zhang BH, Wang $X J$ : Deep sequencing identifies novel and conserved microRNAs in peanuts (Arachis hypogaea L.). BMC Plant Biol 2010, 10:3.

32. Chen X: MicroRNA biogenesis and function in plants. FEBS Lett 2005 , 579(26):5923-5931.

33. Wang $Y$, Itaya A, Zhong X, Wu Y, Zhang J, van der Knaap E, Olmstead R Qi Y, Ding B: Function and evolution of a MicroRNA that regulates a Ca2 + -ATPase and triggers the formation of phased small interfering RNAs in tomato reproductive growth. Plant Cell 2011, 23(9):3185-3203.

34. Johnson C, Bowman L, Adai AT, Vance V, Sundaresan V: CSRDB: a small RNA integrated database and browser resource for cereals. Nucleic Acids Res 2007, 35(suppl 1):D829-D833.

35. Wang X, Elling AA, Li X, Li N, Peng Z, He G, Sun H, Qi Y, Liu XS, Deng XW: Genome-wide and organ-specific landscapes of epigenetic modifications and their relationships to mRNA and small RNA transcriptomes in maize. Plant Cell 2009, 21(4):1053-1069.

36. Tanzer A, Stadler PF: Molecular evolution of a microRNA cluster. J Mol Biol 2004, 339(2):327-335.

37. Zhou M, Sun J, Wang $\mathrm{QH}$, Song LQ, Zhao G, Wang HZ, Yang HX, Li X: Genome-wide analysis of clustering patterns and flanking characteristics for plant microRNA genes. The FEBS journal 2011, 278(6):929-940.

38. Guo L, Lu Z: Global expression analysis of miRNA gene cluster and family based on isomiRs from deep sequencing data. Comput Biol Chem 2010, 34(3):165-171

39. Li A, Mao L: Evolution of plant microRNA gene families. Cell Res 2006, 17(3):212-218
40. Luo X, Gao Z, Shi T, Cheng Z, Zhang Z, Ni Z: Identification of miRNAs and their target genes in peach (Prunus persica L.) using high-throughput sequencing and degradome analysis. PLOS One 2013, 8(11):e79090.

41. Jones-Rhoades MW, Bartel DP: Computational identification of plant microRNAs and their targets, including a stress-induced miRNA. Mol Cell 2004, 14(6):787-799.

42. Wang C, Han J, Liu C, Kibet KN, Kayesh E, Shangguan L, Li X, Fang J: Identification of microRNAs from Amur grape (Vitis amurensis Rupr.) by deep sequencing and analysis of microRNA variations with bioinformatics. BMC Genomics 2012, 13:122.

43. Xia R, Zhu H, An YQ, Beers EP, Liu Z: Apple miRNAs and tasiRNAs with novel regulatory networks. Genome Biol 2012, 13(6):R47.

44. Lau NC, Lim LP, Weinstein EG, Bartel DP: An abundant class of tiny RNAs with probable regulatory roles in Caenorhabditis elegans. Science 2001 294(5543):858-862.

45. Lagos-Quintana M, Rauhut R, Lendeckel W, Tuschl T: Identification of novel genes coding for small expressed RNAs. Science 2001, 294(5543):853-858.

46. Bartel DP: MicroRNAs: target recognition and regulatory functions. Cell 2009, 136(2):215-233.

47. Rhoades MW: Prediction of plant MicroRNA targets. Cell 2002, 110(4):513-520.

48. Lai EC, Tomancak P, Williams RW, Rubin GM: Computational identification of Drosophila microRNA genes. Genome bio 2003, 4(7):R42

49. Bonnet E, Wuyts J, Rouze P, Van de Peer Y: Detection of 91 potential conserved plant microRNAs in Arabidopsis thaliana and Oryza sativa identifies important target genes. P Natl Acad Sci USA 2004 101(31):11511-11516

50. Ashburner M, Ball CA, Blake JA, Botstein D, Butler H, Cherry JM, Davis AP, Dolinski K, Dwight SS, Eppig JT, Harris MA, Hill DP, Issel-Tarver L, Kasarskis A, Lewis S, Matese JC, Richardson JE, Ringwald M, Rubin GM, Sherlock G: Gene ontology: tool for the unification of biology. Nat Genet 2000, 25(1):25-29.

51. Fischer $R L$, Bennett $A$ : Role of cell wall hydrolases in fruit ripening. Annu Rev Plant Biol 1991, 42(1):675-703.

52. Ranocha P, McDougall G, Hawkins S, Sterjiades R, Borderies G, Stewart D, Cabanes-Macheteau M, Boudet AM, Goffner D: Biochemical characterization, molecular cloning and expression of laccases-a divergent gene family-in poplar. Eur J Biochem 1999, 259(1-2):485-495.

53. Guillaumie S, Mzid R, Mechin V, Leon C, Hichri I, Destrac-Irvine A, Trossat-Magnin C, Delrot S, Lauvergeat V: The grapevine transcription factor WRKY2 influences the lignin pathway and xylem development in tobacco. Plant Mol Biol 2010, 72(1-2):215-234.

54. Ye Z-H, Kneusel RE, Matern U, Varner JE: An alternative methylation pathway in lignin biosynthesis in Zinnia. Plant Cell 1994, 6(10):1427-1439.

55. Zhong R, Demura T, Ye ZH: SND1, a NAC domain transcription factor, is a key regulator of secondary wall synthesis in fibers of Arabidopsis. Plant Cell 2006, 18(11):3158-3170.

56. Rubinelli PM, Chuck G, Li X, Meilan R: Constitutive expression of the Corngrass 1 microRNA in poplar affects plant architecture and stem lignin content and composition. Biomass Bioenergy 2013, 54:312-321.

57. Lin JS, Lin CC, Lin HH, Chen YC, Jeng ST: MicroR828 regulates lignin and $\mathrm{H}_{2} \mathrm{O}_{2}$ accumulation in sweet potato on wounding. New Phytol 2012, 196(2):427-440

58. Lu S, Li Q, Wei H, Chang MJ, Tunlaya-Anukit S, Kim H, Liu J, Song J, Sun YH, Yuan L, Yeh T, Peszlen I, Ralph J, Sederoff RR, Chiang VL: Ptr-miR397a is a negative regulator of laccase genes affecting lignin content in Populus trichocarpa. P Natl Acad Sci USA 2013, 110(26):10848-10853.

59. Lu S, Sun YH, Chiang VL: Stress-responsive microRNAs in Populus. Plant $J$ 2008, 55(1):131-151.

60. Hoffmann L, Besseau S, Geoffroy P, Ritzenthaler C, Meyer D, Lapierre C, Pollet B, Legrand M: Silencing of hydroxycinnamoyl-coenzyme A shikimate/ quinate hydroxycinnamoyltransferase affects phenylpropanoid biosynthesis. Plant Cell 2004, 16(6):1446-1465.

61. Pieczenik SR, Neustadt J: Mitochondrial dysfunction and molecular pathways of disease. Exp Mol Pathol 2007, 83(1):84-92.

62. Xie Z, Allen E, Fahlgren N, Calamar A, Givan SA, Carrington JC: Expression of Arabidopsis MIRNA genes. Plant Physiol 2005, 138(4):2145-2154.

63. Subramanian S, Fu Y, Sunkar R, Barbazuk WB, Zhu JK, Yu O: Novel and nodulation-regulated microRNAs in soybean roots. BMC Genomics 2008, 9:160.

64. Kotake T, Hojo S, Yamaguchi D, Aohara T, Konishi T, Tsumuraya Y: Properties and physiological functions of UDP-sugar pyrophosphorylase in Arabidopsis. Biosci, Biotech Bioch 2007, 71(3):761-771. 
65. Chang S, Puryear J, Cairney J: A simple and efficient method for isolating RNA from pine trees. Plant Mol Biol Rep 1993, 11(2):113-116.

66. Meyers BC, Axtell MJ, Bartel B, Bartel DP, Baulcombe D, Bowman JL, Cao X, Carrington JC, Chen X, Green PJ, Griffiths-Jones S, Jacobsen SJ, Mallory AC, Martienssen RA, Poeting RS, Qi Y, Vaucheret $\mathrm{H}$, Voinnet O, Watanabe $Y$, Weigel D, Zhu J: Criteria for annotation of plant MicroRNAs. Plant Cell 2008, 20(12):3186-3190

67. Schwab R, Palatnik JF, Riester M, Schommer C, Schmid M, Weigel D: Specific effects of MicroRNAs on the plant transcriptome. Dev Cell 2005, 8(4):517-527.

68. Livak KJ, Schmittgen TD: Analysis of relative gene expression data using real-time quantitative $P C R$ and the $2^{-\triangle \Delta C T}$ method. Methods 2001, 25(4):402-408.

69. Design R-TPP: Facile means for quantifying microRNA expression by real-time PCR. BioTechniques 2005, 39(4):519-525.

70. Allen E, Xie Z, Gustafson AM, Carrington JC: microRNA-directed phasing during trans-acting siRNA biogenesis in plants. Cell 2005, 121(2):207-221.

71. Benjamini Y, Hochberg Y: Controlling the false discovery rate: a practical and powerful approach to multiple testing. J R Stat Soc $B$ 1995, 57(1):289-300.

doi:10.1186/1471-2164-15-953

Cite this article as: Wu et al: Identification of miRNAs involved in pear fruit development and quality. BMC Genomics 2014 15:953.

\section{Submit your next manuscript to BioMed Central and take full advantage of:}

- Convenient online submission

- Thorough peer review

- No space constraints or color figure charges

- Immediate publication on acceptance

- Inclusion in PubMed, CAS, Scopus and Google Scholar

- Research which is freely available for redistribution 